NBER WORKING PAPER SERIES

\title{
LEVERAGE AND CASH DYNAMICS
}

Harry DeAngelo

Andrei S. Gonçalves

René M. Stulz

Working Paper 28970

http://www.nber.org/papers/w28970

\author{
NATIONAL BUREAU OF ECONOMIC RESEARCH \\ 1050 Massachusetts Avenue \\ Cambridge, MA 02138 \\ June 2021
}

We thank Byungwook Kim for excellent research assistance. The views expressed herein are those of the authors and do not necessarily reflect the views of the National Bureau of Economic Research.

NBER working papers are circulated for discussion and comment purposes. They have not been peer-reviewed or been subject to the review by the NBER Board of Directors that accompanies official NBER publications.

(C) 2021 by Harry DeAngelo, Andrei S. Gonçalves, and René M. Stulz. All rights reserved. Short sections of text, not to exceed two paragraphs, may be quoted without explicit permission provided that full credit, including $\odot$ notice, is given to the source. 
Leverage and Cash Dynamics

Harry DeAngelo, Andrei S. Gonçalves, and René M. Stulz

NBER Working Paper No. 28970

June 2021

JEL No. G31,G33,G35

\title{
ABSTRACT
}

This paper documents new and empirically important interactions between cash-balance and leverage dynamics. Cash ratios typically vary widely over extended horizons, with dynamics remarkably similar to (and complementary with) those of capital structure. Leverage and cash dynamics interact approximately as predicted by the internal-versus-external funding regimes in Myers and Majluf (1984). Leverage is quite volatile when cash ratios are stable and vice-versa, while net-debt ratios are almost always volatile. Most firms increase leverage sharply as cash balances (internal funds) become scarce. Capital structure models that extend Hennessy and Whited (2005) to include cash-balance dynamics explain some, but not all, aspects of the observed relation between cash squeezes and leverage increases.

\author{
Harry DeAngelo \\ University of Southern California \\ Marshall School of Business \\ 701 Exposition Blvd., Ste. 231 \\ Los Angeles, CA 90089 \\ hdeangelo@marshall.usc.edu \\ Andrei S. Gonçalves \\ University of North Carolina \\ 4101 McColl Building, \\ 300 Kenan Center Drive \\ Chapel Hill, NC 27599 \\ andreisalem@gmail.com
}

\author{
René M. Stulz \\ The Ohio State University \\ Fisher College of Business \\ 806A Fisher Hall \\ Columbus, OH 43210-1144 \\ and NBER \\ stulz@cob.osu.edu
}




\section{Leverage and Cash Dynamics}

\section{Introduction}

The empirical corporate finance literature contains two distinct (and enormous) research silos, one focused on capital structure and the other on cash balances, with analysis of interactions between leverage and cash largely ignored. Cash balances are simply not considered in the main descriptive studies of factors that might affect capital structure (Rajan and Zingales (1995), Lemmon, Roberts, and Zender (2008), Frank and Goyal (2009)). The situation is a bit better in studies that seek to explain cash-balance behavior where leverage is often included as a control (e.g., Opler et al. (1999), Almeida, Campello, and Weisbach (2005), Duchin et al. (2016)). Aspects of the interactions between cash balances and capital structure do receive serious attention in a few studies. Most notably, firms deleverage by both paying down debt and growing cash balances (Acharya, Almeida, and Campello (2007), DeAngelo, Gonçalves, and Stulz (2018)), while firms that issue securities often would have run out of cash without the issuance proceeds (DeAngelo, DeAngelo, and Stulz (2010), Denis and McKeon (2012), Huang and Ritter (2021)).

This paper documents a broad set of new and empirically important dynamic interactions between capital structure and cash balances. Time-series variation in leverage depends strongly on cash balances, and vice-versa for time-series variation in cash, with the dynamics of leverage and cash-balance ratios interacting approximately as predicted by the internal-versus-external funding regimes in Myers and Majluf (1984). Leverage is quite volatile when cash ratios are stable and vice-versa, while net-debt ratios are almost always volatile. Firms whose time-series average net-debt ratios are high (low) typically have leverage ratios that are more (less) volatile than their cash ratios. Most firms increase leverage sharply as their cash balances (internal funds) become scarce, despite widespread equity issuances that violate the pecking-order rule for external financing. Moreover, cash ratios tend to vary widely over extended time horizons, just as DeAngelo and Roll (2015) find for leverage.

Two distinct classes of explanations - one target-based, the other funding-related - could account for the typically wide time-series variation in leverage and cash ratios documented in Panel A of Figure 1. If, as Opler et al. (1999, p. 44) hypothesize, firms have leverage and cash-balance targets that share the same 
determinants, then determinant changes that drive changes in a firm's leverage will also drive changes in its cash ratio, so that both types of ratios can be volatile due to variation in their shared underlying target determinants. An alternative explanation is that the volatilities of leverage and cash ratios could largely reflect variation in the extent to which funding needs affect debt and equity issuances and cash-balance drawdowns. Such an explanation is implied by Myers and Majluf's (1984) funding-based analysis of investment-related cash squeezes and by Easterbrook's (1984) conceptually analogous analysis of payoutrelated cash squeezes.

Figure 1, Panel B provides evidence favoring the funding-related explanation over the changing-targets explanation for variation in leverage and cash-balance ratios. This graph documents the ranges of marketleverage (ML), book-leverage (BL), cash-balance (Cash/TA), and net-debt (Net debt/TA) ratios during episodes of stability in ML, BL, or Cash/TA. When ML (or BL) stays in a narrow bandwidth of 0.050 for at least 10 years, Cash/TA tends to vary widely. When Cash/TA stays in a similarly narrow bandwidth for a comparable length of time, ML and BL both tend to be volatile. In all three types of stable episodes, Net debt/TA tends to be volatile, reflecting the typically wide variation in Cash/TA when leverage is stable and the typically wide variation in leverage when Cash/TA is stable.

If firms have leverage and Cash/TA targets with the same determinants, then episodes of stability of one ratio should be associated with stability in the other. Panel B of Figure 1 indicates the exact opposite. Although not depicted in the figure, we also find that stable Cash/TA episodes tend to occur when cashbalance ratios are near zero (as detailed later in the paper), which is a plausible indicator of situations in which firms are likely to be squeezed for cash and thus would seek to raise external funds.

We find that firms tend to increase leverage substantially as they draw down cash balances. We study episodes in which firms move from their historically highest Cash/TA ratio to a later trough, a transition that takes a median of three years in our full sample of 15,013 Compustat firms. Median Cash/TA declines from 0.298 at the peak to 0.044 at the trough, while median market leverage increases from 0.056 to 0.206. Absent external financing, most of these firms would have run out of cash by the trough year. The median firm raises funds equal to $290 \%$ of trough-year cash balances, which means that most of the new funds are 
used to cover outlays that internal funds cannot cover.

When we divide the sample into firms that would have run out of cash absent external financing and firms that did not need outside funds to have positive cash balances, we find that median ML increases markedly from 0.066 to 0.283 for the former group and only slightly from 0.033 to 0.046 for the latter group. In short, the firms that otherwise would have run out of cash tend to increase leverage by large amounts while the remaining firms do not. We also find that cash squeezes are pervasively important when we reverse the sampling approach and analyze levering-up episodes in which a firm moves from its historically lowest leverage to subsequent peak leverage.

The fact that firms tend to increase leverage as they spend down their cash balances is qualitatively consistent with the internal-versus-external funding regimes in Myers and Majluf (1984). This funding element of their theory also captures other prominent regularities that connect variation in leverage and cash ratios. Their theory predicts that firms with negative net debt have time-varying cash ratios (because they use only cash to fund investment) and stable leverage ratios (because they do not borrow until cash is exhausted). It also predicts that firms with positive net debt have time-varying leverage ratios (reflecting the use of external capital to fund investment) and stable cash ratios (because cash has been squeezed to zero). We find radical cross-firm differences in the volatilities of both leverage and cash ratios, with low volatility in one associated with high volatility in the other. And, as Figure 2 shows, firms with low (high) net-debt ratios tend to have cash ratios that are more (less) volatile than their leverage ratios, just as Myers and Majluf's funding-regime predictions would indicate.

With leverage typically increasing sharply when cash is squeezed, it sounds like firms generally adhere to the pecking-order rule for external financing in the sense that debt issuance unequivocally dominates equity issuance. That is not the case empirically. When we examine firms moving from peak Cash/TA to trough, we find a nontrivial minority in which leverage increases because the low proportion of debt issued exceeds the (even lower) pre-issuance debt proportion. In numerous other instances, leverage decreases slightly (or not at all) because firms with near-zero (or zero) leverage issue equity (and no debt) to address cash squeezes. These cases violate the pecking order: The typical firm has virtually no debt outstanding 
and large cash balances, but issues equity and does so when it has spendable cash and the capacity to issue at least some debt (at a minimum by borrowing against that cash).

Importantly, although we find numerous pecking-order violations for external financing, those cases add little to the time-series variation in leverage ratios because equity issuances by firms with near-zero (or zero) leverage induce little (or no) change in leverage. These pecking-order violations are nonetheless especially noteworthy because they cannot be explained either by traditional (static) tradeoff models or by Myers and Majluf's (1984) original theory.

They could, however, be explained by the dynamic capital structure models that we analyze here: Gamba and Triantis (2008, GT) and DeAngelo, DeAngelo, and Whited (2011, DDW). GT and DDW are extensions of Hennessy and Whited (2005, HW) in which debt and cash are determined separately, whereas in HW, only net debt (debt minus cash) is determined, thus rendering HW's model silent on many of the new regularities we document. As with HW, the models of GT and DDW combine the investment-funding motives that are central to the pecking-order theory with the tax benefits and distress costs that are central to traditional tradeoff formulations. Our focus on gauging the explanatory power of GT and DDW thus adheres to Fama and French's (2005, p. 581) bottom line that traditional tradeoff and pecking-order models are dead as stand-alone theories of capital structure, so that researchers should turn to testing frameworks that incorporate elements of both.

Traditional tradeoff theories ignore funding decisions because they hold investment fixed and assume that equity payouts are used only for adjusting the debt-equity mix. They also do not consider cash-balance decisions, much less the nuanced cash-leverage interactions documented here. Nor can such theories explain why any firm would ever have a negative-net-debt capital structure. Myers and Majuf's (1984) theory does have a funding focus (due to endogenous investment) and it can explain negative net debt. It is nonetheless problematic because firms do not follow its predicted external-funding hierarchy. Most notably, as Fama and French (2005) emphasize, firms do not issue equity only as a last resort.

Myers and Majluf's (1984) pecking-order theory has only three dates, whereas GT and DDW and indeed all dynamic models that build on HW have longer (infinite) horizons that create incentives for firms 
not to treat external equity as last-resort financing. The underlying source of those incentives is that financial flexibility in the form of unused debt capacity is valuable for meeting potential future funding needs. HW, GT, and DDW are also distinguished by their use of specific quantitative estimates of model parameters that are selected for their ability to match several statistical moments in the data.

We gauge the ability of the models of GT and DDW to explain the relation at the firm level between cash-balance squeezes and time-series variation in leverage. A distinguishing feature of these tests is that they assess the ability of each model to explain aspects of real-world financing behavior that were not part of the estimation/calibration process used to select parameters. We find that the GT and DDW models explain the qualitative link between leverage increases and cash squeezes at real-world firms, but both fall short quantitatively by predicting squeeze-related increases in market-leverage ratios that are far more muted than we observe in the real data.

We begin in section 2 with some basic results on variation in leverage and cash ratios that provide a foundation for the empirical work that is central to the remainder of this study. Section 3 documents our basic findings on cash-balance and leverage interactions, while section 4 reports findings on the link between cash-balance squeezes and leverage increases. Section 5 examines the ability of GT and DDW to explain our cash squeeze findings. Section 6 briefly summarizes our findings and their main implications.

\section{Time-series variation in leverage and cash-balance ratios: Basic facts}

This section describes our sample and documents four basic regularities about time-series variation in leverage and cash-balance ratios. First, volatility measures for a given firm based on just a few years of data materially understate the variation in these ratios over extended horizons. This regularity is important because most firms do not stay on Compustat for long, and so their data do not yield good descriptions of leverage and cash dynamics. Second, market-leverage, book-leverage, cash-balance, and net-debt ratios all typically exhibit substantial volatility when estimated over extended horizons. Third, there are radical cross-firm differences in the time-series volatility of all four ratios, with high volatility for many firms and modest volatility for a nontrivial number of others. Fourth, there is remarkable similarity in the time-series 
variation (over extended horizons) of the cross-sectional distributions of the four ratios.

\subsection{The sample, basic definitions, and some background on leverage and cash-balance ratios}

We study a sample of 17,245 nonfinancial firms that have at least two consecutive years of non-missing leverage and cash-balance data on Compustat/CRSP within the coverage period of 1950 to $2017 .{ }^{1}$ For some analysis, we focus on the subset of 3,099 firms with non-missing data for at least 20 years because, as section 2.2 documents, data sets in which many firms have just a few years of observations understate the long-horizon time-series variation in firm-level leverage and cash ratios. Firms in the 20-year-plus sample typically account for a large majority of the market value of equity for all sample firms in a given year.

Here and throughout, we define market leverage as $\mathrm{ML}=\mathrm{debt} /[\mathrm{debt}+$ market value of equity $]$; book leverage as $\mathrm{BL}=\mathrm{debt} /$ total assets; the cash-balance ratio as Cash/TA $=$ cash and marketable securities/total assets; and the net-debt ratio as Net debt/TA $=\mathrm{BL}-\mathrm{Cash} / \mathrm{TA}$.

Figure 3 reports wide differences across firms in their typical (time-series median) levels of ML, BL, Cash/TA, and Net debt/TA. The first entry gives the medians of these four ratios across all firms with 20plus years of data. Successive entries give the same median values across firms in each of 10 (decile-based) groups, starting with firms with the lowest $10 \%$ of the ratio in question and working upward.

Three regularities stand out in Figure 3. First, when we consider all firms pooled together, we find typical (time-series median) levels of leverage and cash-balance ratios in the same ballpark as reported in many prior studies. Second, the breadth of cross-firm variation in the typical time-series level of Cash/TA is almost as great as for ML and BL. Third, a large minority of firms with 20-plus years of data (decile groups 1.2 and 3) typically have higher cash balances than debt outstanding so that their time-series median Net debt/TA ratio is negative. The latter point does not imply that negative Net debt/TA is a permanent financial-policy target because such ratios could simply reflect transitory cash holdings that are large for

\footnotetext{
${ }^{1}$ For inclusion in the sample, a firm-year observation must have (i) security codes 10 or 11, (ii) primary SIC codes not in the ranges 4900 to 4949 (utility firms) and 6000 to 6999 (financial firms), and (iii) non-missing data on the book values of debt, assets, and cash and marketable securities. There are 18,726 firms that meet these conditions for at least one year, with 17,245 firms meeting them for at least two consecutive years. For some analysis presented below, key variables are missing from Compustat for some firms, which means that our full-sample analysis is based on fewer than 17,245 firms.
} 
extended periods of time.

Although Figure 3's regularities are important background for the findings reported below, our focus in this paper is not on explaining cross-firm variation in the typical levels of leverage and cash-balance ratios. Our focus is on understanding the dynamics of those ratios for a given firm and, especially, how they interact. We accordingly next discuss some important differences between short-horizon and longhorizon measures of the volatility of leverage and cash-balance ratios.

\subsection{Time-series volatility in leverage and cash ratios over short versus extended horizons}

In Table 1, Panel A reports the standard deviation $(\sigma)$ and range of ML, BL, Cash/TA, and Net Debt/TA for the median firm in the 20-year-plus sample as a function of the number of years of data used to calculate each ratio. The first four columns report $\sigma$ and range figures based on 2, 5, 10, and 20 years of data, while the fifth column uses all available data for each firm in the sample. The data in the fifth column indicate that, over long horizons, substantial time-series variation in leverage and cash-balance ratios is the norm for nonfinancial firms. This leverage finding confirms the central result of DeAngelo and Roll (2015, table I), while the typical firm's high time-series volatility in Cash/TA is a new finding that plays an important role in the connection between leverage and cash-balance dynamics analyzed later in this paper.

For all four ratios, a scan across the rows of Panel A shows substantial truncation of the $\sigma$ and range (from their values based on the full time series) when we use only 2, 5, or 10 years of data. The clear implication is that one should not use just a few years of data to draw inferences about time-series variation over extended horizons in leverage and cash-balance ratios. There are two underlying reasons. The first is the well-known property that, in many familiar stochastic processes, the volatility of the outcome variable increases as shocks arrive and accumulate. ${ }^{2}$

\footnotetext{
${ }^{2}$ A classic example is that the $\sigma$ of the outcome variable in an AR(1) process with a unit root is the baseline $\sigma$ multiplied by the square root of the time horizon. If instead mean reversion is embedded in such a process, the $\sigma$ of the outcome variable also increases with the horizon, but asymptotically approaches a finite limit (Hamilton (1994, p. 53)). In such cases, an estimate of $\sigma$ based on two observations gauges conditional volatility, i.e., the typical movement expected from the current to next period, which depends on only one shock. In contrast, an estimate of $\sigma$ based on a long series of observations gauges unconditional volatility, i.e., the typical extent that the next observation (which reflects the accumulated effects of many shocks) deviates from the overall mean of the process.
} 
The second reason is that the Compustat file contains many small firms that have data available for just a few years. Firms that are on Compustat only briefly are delisted due to financial distress at rates roughly two and one half times the troubled-firm delist rates that we observe among firms with at least 20 years of data. Consequently, unconditional Compustat samples (e.g., our full sample) will tend to yield inferences that are heavily influenced by smaller and more troubled firms, each of which has only a short time series of data available. We accordingly place more emphasis on our sample of firms with at least 20 years of data than we place on our full sample findings.

\subsection{Cross-firm differences in the time-series variation of leverage and cash-balance ratios}

Panel B of Table 1 divides firms in the 20-year-plus sample into 10 decile-based groups sorted on the time-series standard deviation $(\sigma)$ of market leverage (ML), book leverage (BL), the cash-balance ratio (Cash/TA), and the net-debt ratio (Net debt/TA). Row 1 analyzes the sample divided into 10 equal-sized groups ranked on the basis of $\sigma(\mathrm{ML})$, while rows 2,3 , and 4 consider the sample divided into 10 equalsized groups based respectively on $\sigma(\mathrm{BL}), \sigma(\mathrm{Cash} / \mathrm{TA})$, and $\sigma(\mathrm{Net}$ debt/TA $)$. The column labeled "lowest" reports data for the first decile group, i.e., the $10 \%$ of firms with the smallest $\sigma$ in question. The column labeled "group 2" reports data for the second decile group (i.e., the $10 \%$ of firms with the next largest $\sigma$ ), and so on up to the column labeled "highest," which has the $10 \%$ of firms with the largest $\sigma$.

We find radical differences across firms in the volatility of ML, BL, Cash/TA, and Net debt/TA. For example, in the highest $\sigma(\mathrm{ML})$ group, the median firm has $\sigma(\mathrm{ML})$ of 0.257 , which is 8.3 times the median $\sigma(\mathrm{ML})$ of 0.031 in the lowest group (row 1, Panel B, Table 1). BL, Cash/TA, and Net debt/TA also show large differences in volatility across the lowest $\sigma$ versus highest $\sigma$ groups (far-right column). The net-debt ratio shows the smallest such difference since even the lowest $\sigma(\mathrm{Net}$ debt/TA) group exhibits non-trivial volatility. Indeed, for every group, Net debt/TA exhibits the highest volatility, followed by ML, BL, and Cash/TA (for each column in Panel B, scan across all rows).

We also find that that low (high) time-series volatility of ML, BL, and Cash/TA all come with a tendency for firms to have low (high) levels of the ratio in question, whereas the reverse is true for Net debt/TA. These tendencies are evident in Panel C of Table 1, which employs the same volatility-based 
partitioning as in Panel B. These tendencies are key to understanding the typical interactions between leverage and cash-balance ratios, as will become clear in section 3 below.

\subsection{Time-series variation in the leverage and cash-balance cross sections}

Figure 4 documents the extent of variation over time in the cross-sectional distributions of Cash/TA, ML, BL, and Net debt/TA. The empirical approach follows DeAngelo and Roll (2015, figure 3) who analyze the BL cross section. The figure plots the average R-square for simple regressions whose inputs differ by $\mathrm{T}$ years, ranging from $\mathrm{T}=1$ (adjacent years) to $\mathrm{T}=40$ (cross sections 40 years apart). In each case, the right-hand side of the regression has a constant and the value of one of the four ratios in a "base year" while the left-hand side variable is the value of the same variable T years forward in time. ${ }^{3}$

Figure 4 shows that the pattern of intertemporal instability in the cross section of Cash/TA ratios is virtually identical to the cross-sectional instability patterns for market leverage, book leverage, and the netdebt ratio. Consistent with DeAngelo and Roll's (2015, figure 3) analysis of the BL cross section, the norm for all four ratios is modest changes in the cross section over a few years and major "scrambling" thereof over extended horizons. Intuitively, if a firm has relatively high (or low) values of Cash/TA or leverage today, then it tends to have high (or low) values of the same ratio over the next few years. However, the R-square plot in Figure 4 indicates that the ability of today's Cash/TA and leverage ratios to predict high (or low) future values of those ratios erodes significantly after the first few years. The erosion is sharp over the next ten years or so and continues thereafter, albeit at a slower pace. Eventually, the very low R-squares indicate that future cross sections bear almost no resemblance to today's cross section.

Note that Figure 4 shows that the "scrambling" of the cash-balance and leverage cross sections evolves in similar fashion when viewed on a univariate basis. It is silent about co-movement over time in the cashbalance and leverage ratios of a given firm. Sections 3 and 4 analyze the latter issue.

\footnotetext{
${ }^{3}$ For example, for $\mathrm{T}=1$, the $\mathrm{R}$-square reported in the figure is the average of R-squares for regressions pairing 1950 with 1951, 1951 with $1952, \ldots$, and 2016 with 2017 . For $\mathrm{T}=2$, the reported R-square is the average of R-squares pairing 1950 with 1952, 1951 with $1953, \ldots$, and 2015 with 2017. And so on for longer gaps between years. A firm is included in a given pair if and only if it has the relevant data on Compustat for both years. Figure 4 is based on firms in the 20-year plus sample. Similar R-square plots obtain when we use our full sample.
} 
The "scrambling" of the cash-balance cross section in Figure 4 indicates that a firm's Cash/TA ratio today is a poor predictor of its Cash/TA ratio over extended horizons. This inference might seem to be contradicted by Dittmar and Duchin's (2011, abstract, DD) main carry-away that "firms monotonically and substantially decrease their cash holdings over the corporate life-cycle." However, there is no contradiction, since what DD show is that the cross-firm average Cash/TA ratio is higher among younger firms (than it is among older firms). Intuitively, the high volatility of Cash/TA (per our Table 1-3) means that any firm can have large increases in its cash ratio later in its lifecycle, while what DD show is that the typical older firm has a lower cash ratio than the typical younger firm. In any case, the important point for Figure 4 is that the volatility in Cash/TA is sufficiently large at many firms so that it becomes hard to predict the cashbalance cross section over extended horizons.

\section{Leverage and cash-balance interactions}

This section documents a broad set of findings on the interactions between leverage and cash-balance ratios. The main general regularities are that net-debt ratios almost always exhibit substantial time-series volatility, with relatively stable market and book leverage ratios tending to accompany volatile cash ratios, and vice-versa. The data are also consistent with the hypothesis that the squeezing of cash balances is associated with greater time-series variation in leverage. Section 4 explores the latter issue.

\subsection{Net debt and the relation between leverage and cash-balance ratios}

Table 2 documents the relations between the levels and volatilities of leverage and cash-balance ratios for firms in the 20-year plus sample sorted into 10 groups based on each firm's time-series median Net debt/TA ratio. This sample partitioning is a useful place to begin our analysis of leverage-cash balance interactions because the net-debt ratio embeds both debt obligations and cash holdings.

Table 2 reveals large cross-firm variation in the typical level of Net debt/TA, with the median firms in the lowest and highest decile-based groups having time-series median levels of Net debt/TA of -0.374 and 0.415 respectively (row 1). The three lowest groups have negative median Net debt/TA levels, indicating that, over their 20-plus year histories, almost $30 \%$ of sample firms more often than not had higher cash 
holdings than debt obligations (row 1). For groups 1-8, the median firm has had negative net debt at least once in its life (row 7) and positive net debt at some other time (row 8). In sum, negative-net-debt capital structures are commonplace and typically transitory features of financial policy.

For all 10 groups in Table 2, the median firm exhibits large time-series variation in Net debt/TA (row 4), but the contributions of leverage and cash balances to the volatility of Net debt/TA differ radically across groups. Firms at the low end of the Net debt/TA spectrum tend to have low market leverage (ML) volatility coupled with high Cash/TA volatility, while those at the opposite end of the spectrum tend to have high ML volatility coupled with low Cash/TA volatility (rows 5 and 6). Firms at the low end of the spectrum tend to have high time-series median levels of Cash/TA and low time-series median levels of ML, while those at the opposite end tend to have high ML ratios paired with low Cash/TA ratios (rows 2 and 3). The data further show that the typical firm in most groups has had (i) conservative leverage at some point in time and markedly positive leverage at another time (rows 9 and 10) and (ii) a Cash/TA ratio near zero at one point and markedly positive at another (rows 11 and 12).

The key carry-away from Table 2 is that high volatility in Net debt/TA is pervasive, with ML tending to be less (more) volatile - both in absolute terms and relative to Cash/TA volatility - at firms where cash balances are large (small) relative to debt. The fact that ML tends to be volatile at firms for which cash is scarce and much less variable when cash holdings are high is consistent with the internal versus external funding regime behavior in Myers and Majluf (1984). More generally, it is what one would expect if the squeezing of cash balances encourages firms to issue debt to cover their funding needs.

\subsection{Time-series levels and volatilities: Leverage and cash-balance ratios}

Table 3 examines cross-firm differences in the relations between the levels and volatilities of leverage and cash-balance ratios. Columns (1) and (2) analyze the sample of firms with 20-plus years of data sorted (in panels A, B, and C) by each firm's time-series median level of ML, BL, and Cash/TA. Columns (3) and (4) analyze the same sample sorted (again in panels A, B and C) by the time-series standard deviation of the three ratios. For brevity, Table 3 restricts attention to the lowest $10 \%$ of firms for a given sample sort (columns (1) and (3)) and the highest 10\% (columns (2) and (4)). Our conclusions are unchanged when 
we include the middle $80 \%$ of observations; see Tables IA 1 and IA 2 of the Internet Appendix.

Table 3 indicates that firms with low time-series median levels of leverage (ML or BL) tend to have low leverage volatility coupled with high and volatile Cash/TA ratios, while firms with high levels of ML or BL tend to have high leverage volatility coupled with low levels of, and volatility in, Cash/TA (rows 18 , columns (1) and (2)). This pattern is consistent with the idea that firms with high leverage tend to be facing cash-balance squeezes that lead to greater use of debt, hence to more volatile ML and BL.

In the Table 3 sorting by the time-series median level of Cash/TA, firms with low (high) Cash/TA tend to have high (low) levels of ML and BL (rows 12-14, columns (1) and (2)). We also find that firms with low volatility of Cash/TA tend to have low levels of Cash/TA and high levels of ML and BL (rows 12-14, column (3)). The latter firms also tend to have ML and BL volatilities that are much higher than their Cash/TA volatility (rows 9-11, column (3)). As with the Net debt/TA sorts in Table 2 and with the ML and BL sorts in Panels A and B of Table 3, these findings are consistent with the view that the squeezing of cash balances leads to generally higher and more volatile ML and BL ratios.

Note that, although firms with high Cash/TA volatility typically have ML and BL volatilities that are much lower than their Cash/TA volatility, these leverage volatilities nonetheless tend to be large in absolute terms (rows 9-11, column (4), Table 3).

The latter regularity reflects the fact - discussed at length in section 4 - that firms facing cash squeezes tend to raise debt and hold a nontrivial portion of the issuance proceeds as cash balances. Such actions increase leverage and cash-balance ratios, thereby plausibly bolstering variation in both. The stockpiling of issuance proceeds in cash balances can similarly account for why, when scanning across the columns of Table 3, we see no clear relation linking greater leverage volatility to higher or lower Cash/TA volatility.

\subsection{Episodic stability of leverage and cash-balance ratios}

In the first four columns of Table 4, we analyze episodes in which ML, BL, Cash/TA, and Net debt/TA remain in a bandwidth of 0.050 for at least 10 consecutive years. In the last four columns of the table, we examine episodes in which Cash/TA or ML are consistently low (below 0.050) or consistently high (at least 0.300). The rows of the table report summary statistics on the time-series standard deviations, ranges, and 
median levels of ML, BL, Cash/TA, and Net debt/TA during the episodes specified in the column header. All firms analyzed in Table 4 are from our 20-year-plus sample.

We find that a nontrivial minority of firms has reasonably lengthy episodes in which leverage or cashbalance ratios are quite stable, but ML (or BL) and Cash/TA are rarely stable simultaneously. Specifically, about one fourth of sample firms have an episode in which ML or BL remains in a bandwidth of 0.050 for at least 10 years, while about two fifths have a period of similar length in which the Cash/TA ratio remains comparably stable (Table 4 , panel 1 , first three columns). In sharp contrast, only $1.8 \%$ of firms have an episode in which the Net debt/TA ratio remains stable (panel 1, fourth column), which indicates that at least one of its constituents - BL or Cash/TA - generally changes enough so that the 0.050 bandwidth condition is almost always violated.

Table 4 further shows that, when ML is stable, Cash/TA is typically quite volatile. For the median firm, $\sigma(\mathrm{ML})$ is 0.010 while $\sigma(\mathrm{Cash} / \mathrm{TA})$ is roughly nine times larger at 0.093 , while range(ML) is 0.033 and range(Cash/TA) is also about nine times larger at 0.315 (panel 2, second column). A similar relation holds for stable BL episodes where the median firm's standard deviation and range of Cash/TA is about eight times as great as for BL (panel 2, second column).

Importantly, Table 4 shows that stable Cash/TA episodes tend to arise when firms have low Cash/TA ratios and their ML and BL ratios are both high and volatile (panel 2, third column). This finding is suggestive of a squeeze on cash balances leading firms to borrow more and, in so doing, increasing the volatility of their leverage ratios.

Table 4 further indicates that episodes of leverage stability tend to occur when (i) leverage ratios are low (as reported by DeAngelo and Roll (2015)) and (ii) Cash/TA ratios are both high and volatile. There is a strong propensity for firms in stable ML (or BL) regimes to have no debt at all outstanding and negative net-debt capital structures (panel 3, first two columns). The latter pattern is also suggestive of a link between cash squeezes and leverage volatility, as an abundance of cash is associated with small (or no) borrowing and low volatility of leverage ratios.

The latter point is reinforced by the data in the last four columns of Table 4 . These data indicate that 
episodes of consistently high Cash/TA ratios tend to have contemporaneous ML and BL ratios that are stable and close to 0.000 , while episodes of low Cash/TA tend to have contemporaneous ML and BL that are volatile at levels well above 0.000 (panel 2, fifth and sixth columns). Conversely, episodes of consistently high ML tend to have low and stable Cash/TA, while episodes of consistently low ML tend to have high and volatile Cash/TA (panel 2, last two columns).

\section{Cash-balance squeezes and time-series variation in leverage}

This section documents a strong, but not universal, propensity for firms to lever up sharply when raising outside capital to avoid running out of cash. The data show considerable heterogeneity in the marginal debt-equity mix used to raise outside funds, with most firms issuing at least some debt, and a nontrivial minority issuing only equity to address cash-balance squeezes. The latter firms tend to have low leverage when their cash is squeezed to low levels and so, in marked contrast to most firms, their external financing contributes little to the time-series variation in their leverage ratios. We also find that cash squeezes are far more important for levering-up than for deleveraging episodes. Finally, capital expenditures are typically large at firms that are squeezed for cash, while equity payouts are negligible for the median firm in the full sample, but are a nontrivial fraction of capital expenditures for the median cash-squeezed firm that is listed at least 20 years.

\subsection{Leverage increases as firms move from peak Cash/TA to trough}

Table 5 analyzes cash-balance and leverage ratios for firms at their all-time peak Cash/TA ratio and at the later trough, defined as the lowest Cash/TA ratio attained within 10 years after peak. For brevity, we focus on the full sample results in panel A because the results for the 20-year-plus sample in Panel B are similar to the findings for the full sample.

In Table 5, the median firm in the full sample has a Cash/TA ratio of 0.298 at the peak and 0.044 at the later trough (panel A, rows 1 and 2). Although both the large decline in Cash/TA and its low value at the trough are fully consistent with a substantial cash squeeze, these measures tend to understate the size of the cash squeezes that sample firms typically face. The important problem is that one cannot always detect a 
squeeze from the observed level of Cash/TA because firms facing a squeeze have incentives to raise funds and hold some of the issuance proceeds as cash. That external financing response increases observed Cash/TA to a higher (usually much higher) level, thereby creating the false impression that the firm was not squeezed for cash. Denis and McKeon (2021) analyze this issue and show that it is an important consideration in understanding the long-term secular increase in average cash ratios first documented by Bates, Kahle, and Stulz (2009).

We accordingly gauge cash squeezes by calculating an "as if" or hypothetical Cash/TA ratio that removes the actual external financing proceeds (raised between peak Cash/TA and trough) from the numerator and denominator of the Cash/TA ratio. The hypothetical ratio tells us what Cash/TA would have been if a firm kept all other decisions (investment, payouts, etc.) that it made, but did not raise outside funding. A negative value of the hypothetical Cash/TA ratio is an unequivocal sign of a cash squeeze: It indicates that the firm would have run out of cash and been unable to execute its other decisions if it had not raised more capital.

Table 5 shows that the hypothetical (no external-financing) Cash/TA ratio is -0.110 for the median sample firm (panel A, row 3, first column). Without external funds, most firms would have been far from able to carry out the other aspects of their operating and financial policies. Another intuitive way to see the typical depth of cash squeezes is to note that capital raised is $290 \%$ of cash held at the trough for the median firm (row 4), which indicates a need to raise a lot of outside capital to be able to maintain its other decisions as Cash/TA declines from peak to trough.

Perhaps the most striking regularity in Table 5 is that firms that would have run out of cash tend to increase ML by large amounts, while the remaining firms typically have only minor increases in ML. The second and third columns of the table divide the sample into firms that would have run out of cash absent external financing and firms that did not need external funds to have positive cash balances. Firms that would have run out of cash typically raise large amounts of capital while the firms that would not have run out of cash typically raise almost no new capital (panel A, row 4). Median ML increases from 0.066 to 0.283 for the former group and from 0.033 to 0.046 for the latter (rows 5 and 6). 
In the last four columns of Table 5, we partition the sample according to the percentage of external financing (over the period from a firm's peak Cash/TA to the later trough) that was raised through debt issuance. We use $\delta$ to denote that percentage, with $\delta=100 \%$ indicating that all external financing came in the form of debt and $\delta=0 \%$ indicating that all such financing came from equity.

In our full sample, $56 \%$ of firms either issue all debt or more debt than equity to address their cash squeezes (Table 5, panel A, row 9, fourth and fifth columns). Median ML increases from 0.130 to 0.349 for firms that issue only debt, and from 0.085 to 0.340 for firms that issue more debt than equity (rows 5 and 6, fourth and fifth columns). For firms that issue less debt than equity, ML increases by a smaller, but still economically material, amount from a median of 0.008 to 0.103 . ML increases because the marginal proportion of debt for the typical firm exceeds the initially low (near-zero) median proportion of debt.

A remarkably large subset of firms $-26 \%$ in the full sample - issue only equity as their Cash/TA ratios move from peak to trough. The typical change in leverage is trivial, with median ML falling from 0.023 to 0.006. The explanation is straightforward: When firms with near-zero leverage ratios issue more equity, their marginal debt-financing proportion is only slightly below the initial debt proportion.

The high incidence of equity issuances by firms with almost no debt is, of course, difficult to reconcile with Myers and Majluf's (1984) pecking-order theory and with standard tradeoff theories in which taxes create an incentive for firms to include material amounts of debt in their capital structures.

However, equity issuances by firms with low leverage can occur in dynamic capital structure models of the type tested in section 5. In those models, firms issue equity to bolster financial flexibility - expand debt capacity and/or stockpile cash balances - that can be used to address future funding needs. Figure 5 offers a hint that such flexibility motives may be at work in the pure equity-issuance episodes $(\delta=0 \%)$ in Table 5. Relative to the sample as a whole, those episodes entail a much lower incidence of firms that would have run out of cash without external funds and a much higher incidence of firms that would have had a Cash/TA ratio above 0.100 even without raising more capital.

\subsection{Cash squeezes when firms lever up}

When we reverse the cash-based sampling approach of Table 5 and instead isolate situations in which 
firms are levering up, we find that they are typically experiencing large cash squeezes. Table 6 examines firms that move from all-time trough levels of ML and Net debt/TA to subsequent peak levels, which are defined as the highest values of the ratio in question over the 10 years after the trough. For both ratios and for both our full sample and 20-year-plus sample, the median firm faces a massive cash squeeze while levering up (row 3 and 4). A large majority of firms would have run out of cash without raising outside funds (row 9) and the median ML and Net debt/TA ratios increase by notably larger amounts among firms that would have run out of cash (rows 5 and 6, second, third, fifth, and sixth columns). In sum, substantial cash squeezes underlie the typically large increases in leverage as firms move from trough to peak.

Figure 6 juxtaposes the importance of cash squeezes in levering-up versus deleveraging episodes. The levering-up episodes for market leverage (ML), book leverage (BL), and the net-debt ratio (Net debt/TA) are as defined in Table 6, with each firm being tracked from its historical trough to the highest point attained over the next 10 years. The deleveraging episodes are defined symmetrically, with each firm being tracked from its historical peak ML, BL, and Net debt/TA ratio to the lowest point attained over the next 10 years.

Figure 6 documents that the importance of cash squeezes is far greater in three respects for levering-up episodes than for deleveraging episodes. First, the median firm that is levering up raises outside capital that is more than $400 \%$ of its ending cash balances, while the median firm that is deleveraging raises capital that is around one-quarter to one-third of its ending cash balances (panel A). Second, absent external funding, the median levering-up firm would have had a hypothetical Cash/TA ratio that is deeply negative while the median deleveraging firm would have had a small positive Cash/TA ratio (panel B). Third, the percent of levering-up firms that would have run out of cash absent external funding is at least twice the percent of deleveraging firms that would have run out of cash (panel C).

The asymmetric incidence of cash squeezes for levering-up versus deleveraging episodes points to the relevance of theories in which funding needs are key drivers of time-series variation in leverage.

\subsection{Capital expenditures and payouts when cash balances are squeezed and/or firms lever up}

Table 7 documents the scale of capital expenditures and equity payouts for firms facing cash-balance squeezes (as in Table 5) and for firms that lever up (as in Table 6). We focus on capital expenditures and 
payouts because they are the main uses of funds in the theories we test in the remainder of the paper. They are accordingly the key decision variables in those theories that can generate squeezes on internal funds that might lead firms to seek external funds and, in so doing, alter their leverage ratios.

In Table 7, we report results for all cash squeezes, for cash squeezes addressed by issuing solely equity, and for levering-up episodes defined in terms of trough-to-peak movements in ML, BL, and Net debt/TA. We measure capital expenditures and payouts as a fraction of total assets at the end of the cash-squeeze or levering-up episode (panels 1 and 2) and payouts as a fraction of the sum of capital expenditures and payouts during the episode in question (panel 3).

For all types of episodes, capital expenditures are quite large for the median firm that would have run out of cash without external financing (Table 7, panel 1, first and third columns). They are smaller, but still large, for the median firm that would not have run out of cash (second and fourth columns). The size of the median firm's capital expenditures is especially large for the sample of firms that are listed more than 20 years (third and fourth columns).

For all types of episodes in Table 7, equity payouts are negligible for the median firm in our full sample (panel 2, first and second columns) and are nontrivial for the median firm that has been listed at least 20 years (third and fourth columns). Payouts also account for a nontrivial fraction of the total (capital expenditure plus payouts) use of funds for the median firm in the 20 -year-plus sample, but not in the full sample (panel 3). These findings are consistent with the familiar lifecycle-theory predictions that payouts are small or zero for young firms (which dominate our full sample) and economically material for mature firms (which dominate our 20-year-plus sample).

\section{Can Dynamic Capital Structure Models Explain Our Cash-Squeeze Findings?}

In this section, we gauge the ability of the models of Gamba and Triantis (2008, GT) and DeAngelo, DeAngelo, and Whited (2011, DDW) to explain our findings on cash squeezes and leverage variation. Our decision to focus on these two cash-balance-related extensions of Hennessy and Whited (2005, HW) reflects HW's pioneering role in providing a tractable dynamic analysis of capital structure that (i) incorporates 
elements of standard tradeoff theories coupled with pecking-order-like assumptions about the differential costs of raising debt and equity, and that (ii) has a role for cash stockpiling and drawdowns. HW treat net debt (debt minus cash) as the firm's capital structure choice variable, so that debt and cash are not separately determined, thus rendering their model silent about debt and cash dynamics viewed separately.

We accordingly examine GT and DDW because they are the two earliest (and most basic) extensions of HW in which debt and cash balances are each determined, which means that both models can potentially explain the leverage/cash findings we document. We do not run a "horse race" between GT and DDW, but rather focus on assessing whether or to what extent both point to the same model strengths and weaknesses of HW-style models to explain our cash-squeeze/leverage findings.

In the Appendix, we detail the specific GT and DDW formulations that we analyze. Here, we briefly summarize the key features of those formulations. Both GT and DDW provide predictions about the timeseries properties of leverage and cash ratios using a dynamic (tax versus distress cost) tradeoff structure, with specific parameter values determined through estimation/calibration exercises.

With two exceptions, the GT model that we assess matches the calibration in their paper, which starts with HW's framework, adds an assumption that firms face debt-issuance costs of $2 \%$, and selects parameter values based on HW, Titman and Tsyplakov (2007), and Moyen (2004). The first exception is that we add DDW's assumption that the return earned on cash balances is below the return a firm pays on safe debt. We add this "liquidity discount" because, when firms face only debt-issuance costs as in GT, they never choose to pay down debt and instead always deleverage by accumulating cash. That prediction is at strong odds with real-world deleveraging and thus renders uninteresting the GT formulation with only debtissuance costs. The second exception is that we modify the dynamics of the exogenous productivity/profitability variable to match the model in DDW so that we know differences across the two models are driven by the parameters related to endogenous decisions.

We consider DDW's formulation that includes both a liquidity cost of holding cash and debt-issuance costs, so that both debt and cash balances are strictly determined and firms repay debt and do not simply grow cash balances to deleverage. As in GT, we select parameters through calibration, not a full structural 
estimation. Specifically, we include a 2\% debt issuance cost (the same cost as in GT) and adjust some other parameters relative to DDW's estimates so that our final calibrated model is in line with data moments in DDW. ${ }^{4}$ We use the label "baseline" to distinguish these model specifications from other specifications we investigate because of empirical shortcomings of DDW and GT that our analysis uncovers.

Table 8 gauges the ability of the DDW and GT models to explain the cash-squeeze findings in our Table 5. We do independent runs of each model to obtain 11 samples that match the real sample (used in Table 5) in terms of the number of firms and years of available data. Within each such sample, we focus on model-generated episodes that match the criteria for cash-squeeze episodes to be included in Table 5 .

In the first column of Table 8, we summarize key market and book leverage (ML and BL) features of the actual cash-squeeze episodes at real-world firms. The next two columns examine the baseline specification and report median values (across the 11 model-generated samples) of those ML and BL variables in the model episodes that correspond to the actual cash-squeeze episodes studied in Table 5. We use 11 panels (instead of 10, as in DDW's estimation procedure) so that our medians reflect values in at least one of the simulated panels.

Table 8 addresses three key questions. First, do the DDW and GT models exhibit increases in ML and BL when firms are squeezed for cash? Second, do the models predict larger leverage increases during squeeze episodes when firms would have run out of cash absent external funding? Third, do predicted ML and BL ratios typically increase by much larger amounts when firms would have run out of cash absent outside funding?

The answers to the first two questions are yes. For both the full sample and the 20-year-plus sample, the baseline DDW and GT models predict an increase in ML and BL during cash-squeeze episodes, with larger leverage increases when the firm would have run out of cash had it not raised external funds (baseline

\footnotetext{
${ }^{4}$ In addition to the $2 \%$ debt-issuance cost, the baseline calibrated version of DDW that we test has (i) profitability shock volatility of $35 \%$ (up from $28.4 \%$ in DDW), (ii) a real interest rate of $2 \%$ (up from $1.5 \%$ ), (iii) an upper-debtlimit-to-steady-state capital stock ratio of $60 \%$ (down from $71.9 \%$ ), and (iv) a liquidity (or agency) cost of holding cash of $0.35 \%$ (down from $0.70 \%$ ), which the analysis of Binsbergen, Diamond, and Grotteria (2019) indicates is a better estimate of the liquidity rate-of-return discount on cash holdings.
} 
columns, rows 1-4 of panels A and B, Table 8).

The answer to the third (quantitative) question is no. The baseline DDW and GT models do not exhibit the large differential increase of leverage at firms that would have run out of cash. The differential ML increases are small in all cases (baseline columns, row 5, panels A and B, Table 8). The DDW model predicts a moderate differential change in BL ratios, but a differential that is still notably below that in the real data for the full sample (baseline columns, row 6, panel A) and below, but not as far below, for the 20year-plus sample (panel B). In the GT model, the predicted differential change in BL is far below the differential increase observed in the real data for both samples (again, see row 6, panels A and B).

In the remaining columns of Table 8 , we investigate three ways of possibly improving the predictive ability of both the DDW and GT models by adding further pressures (beyond the liquidity cost in the baseline specification) for cash squeezes to lead to leverage increases. In all three cases, we introduce changes to the baseline formulation that make it more likely that firms face a large cash squeeze. The fourth and fifth columns of Table 8 report model predictions when the liquidity cost is $1.10 \%$ per period (roughly triple the $0.35 \%$ baseline discount on cash balances). The sixth and seventh columns report results for a model specification in which the unconditional distribution of operating income at steady-state can go negative by as much as $15 \%$ of steady-state physical capital, which would of course deepen a firm's need for funds. The last two columns report results for a specification in which the firm must pay out at least $2 \%$ of book equity each period, which treats equity payouts as a mandatory funding need, which will also deepen a cash squeeze.

These three model adjustments do not repair the quantitative empirical shortcomings of the baseline formulations of either model. The predicted differential increase in ML always remains small when the firm would have run out of cash absent external funding (row 5, panels A and B, Table 8). Although the modified formulations of both models lead to a predicted differential BL increase that exceeds the baseline formulation, the main overall message is that neither consistently predicts differential BL changes as large as in the real data.

In Table 9, we gauge how well the DDW and GT models do in terms of predicting the depth of cash 
squeezes that real-world firms typically face when levering up as reported in Table 6. The real data show that firms that would have run out of cash would typically have had strongly negative cash balances absent external funds. The depths of those cash squeezes are reproduced in the first column of Table 9; see the odd-numbered rows.

The baseline version of the GT model predicts large cash squeezes for all three levering up episodes in Table 9 (third column, odd-numbered rows). In many cases, the depth of the cash squeeze markedly exceeds that in the real data. We view the latter over-shooting as not as important as undershooting would be. The reason is that the model predicts a strong interdependency between cash squeezes and levering up, which is the fundamentally important feature of the cash-squeeze evidence documented here.

The main shortcoming for DDW is for the full sample where the predicted cash squeeze lags well below that of the real data (first versus second columns, odd-numbered rows, panel A). This problem for the full sample remains when we consider the three modifications to the DDW baseline model in Table 8 . The DDW model under-predicts the depth of cash squeezes even when firms face high liquidity costs, possibly negative operating profits, or mandatory minimum equity payouts. However, the same problem for the DDW model is not present for the 20-year-plus sample (panel B).

The latter point is good news for HW-style models in the sense that we should largely be concerned about the ability of such models to explain leverage and cash dynamics over extended horizons. The reason, as detailed earlier in the paper, is that unconditional Compustat samples contain many firms with just a few years of data and focusing on such snippets can be misleading about the nature of within-firm dynamics.

In any case, we draw two main conclusions from Tables 8 and 9. First, the DDW and GT models generally do a good job predicting the qualitative relation between cash squeezes and leverage increases that we find in the real data. Second, the ability of DDW and GT to come close to predicting the strong quantitative linkage in the real data (between cash squeezes and leverage increases) is, at best, a mixed bag. The most notable shortcoming is the across-the-board failure of the DDW and GT models to predict the sharp differential increase in ML ratios that typically occurs at real-world firms that face a cash squeeze and that would have run out of cash absent outside funding. 
The latter model failure is noteworthy because an advertised feature of these models is their ability to offer quantitative predictions that can be checked against quantitative real-world measures. The quantitative failures we document are robust in the sense that the failures remain even when we consider substantial movements in model parameters away from their baseline values.

While the models are disappointing because of the latter failures, there are two reasons to be optimistic about these models, given our findings in Tables 8 and 9. First, it takes a theory to beat a theory - and both the DDW and GT models capture qualitative features of real-world interactions between cash squeezes and leverage dynamics that are simply not present in standard tradeoff models which, by construction, ignore debt-cash interactions. Second, and relatedly, the DDW and GT formulations offer a foundation that can incorporate other frictions that can help explain the quantitative strength of the cash-squeeze/leverage relations documented in this paper.

\section{Summary and implications of main findings}

We find that leverage dynamics are related to cash balances approximately as predicted by the internalversus-external funding regimes in Myers and Majluf (1984), despite many equity issuances that violate their pecking-order rule for external financing. Time-series variation in leverage differs radically across firms, with cash-balance interactions key to understanding why leverage is quite volatile at most firms and varies only modestly at a nontrivial minority. When market leverage (ML) or book leverage (BL) is relatively stable, Cash/TA ratios are quite volatile and, when Cash/TA is stable, ML and BL tend to be quite volatile. Net debt/TA ratios accordingly tend to be volatile across the board, including for the large minority of firms with negative time-series median Net debt/TA ratios, i.e., with cash balances that more often than not exceed outstanding debt. The typically large within-firm variation of cash-balance ratios manifests in large variation over time in the Cash/TA cross-section, which becomes "scrambled" (much less similar) over time in a way that is remarkably like the extent of "scrambling" of the leverage cross-section.

Most firms lever up sharply as cash balances are squeezed to low levels and, when we screen for large increases in leverage, we find a strong tendency for firms to have large underlying cash-balance squeezes. 
Cash squeezes are associated with leverage increases because of the strong (but not universal) propensity for firms to issue debt when they would run out of cash absent external funds. A non-trivial minority of cash squeezes are resolved by firms issuing equity, but these cases contribute little to time-series variation in leverage because these issuers tend to have low leverage to begin with. Investment outlays are important components of cash squeezes at most sample firms, while payouts are also a material (albeit typically smaller) use of funds that lead to cash squeezes at firms listed for 20 or more years on Compustat.

Viewed most broadly, our findings indicate a need to move away from the silo structure of the empirical corporate finance literature by treating capital structure and cash balances as complementary elements of financial policy that are both tied to the funding of investment and payout decisions.

We take a step down the latter path by gauging the ability of the dynamic models of Gamba and Triantis (2008, GT) and DeAngelo, DeAngelo, and Whited (2011, DDW) to explain the relation between cash squeezes and leverage increases that we document. We focus on GT and DDW because they are the two earliest and most prominent cash-balance-related extensions of Hennessy and Whited's (2005) dynamic capital structure model. We find that GT and DDW are qualitatively consistent with the real data in that they predict that market- and book-leverage ratios increase as firms are squeezed for cash. The main shortcoming of these models is quantitative, as they predict market-leverage increases that are far smaller than the substantial leverage increases we observe in the real data.

We view our findings on GT and DDW as provisionally encouraging. They are encouraging in that they indicate that models of the Hennessy and Whited (2005) class offer predictions roughly consistent with our new findings on cash squeezes and leverage increase. We view them as provisionally so because fully credible models would predict large leverage increases when firms face cash squeezes of the scale we find in the real data. In short, GT and DDW offer a decent start, but not the final word, on explaining the new regularities documented here. There is accordingly a clear need for theorists and empiricists to drill more deeply into understanding the link between cash squeezes and leverage variation. 


\section{Figure 1}

\section{Median Time-Series Range of Leverage and Cash-Balance Ratios}

The sample contains 3,099 nonfinancial firms with at least 20 consecutive years of non-missing values on Compustat of total book assets, the market value of common stock, and holdings of cash and marketable securities. Panel A reports the value for the median firm of the time-series range (over all sample years) of the market-leverage (ML), book-leverage (BL), cash-balance (Cash/TA), and net-debt (Net debt/TA) ratios. Panel B reports the median range of these ratios during three distinct types of stable episodes. The episodes of stable market leverage are instances in which ML remains in a bandwidth of 0.050 for at least 10 years. Stable episodes for BL and Cash/TA are similarly defined as cases in which the ratio in question remains in a bandwidth of 0.050 for at least 10 years. For each firm, we consider only the longest stable episode (for a particular ratio). Many firms do not have stable episodes: Among the 3,099 firms in the sample, 781 firms have a stable ML episode, 758 firms have a stable BL episode, and 1,267 firms have a stable Cash/TA episode. For brevity, Panel B excludes episodes in which Net debt/TA is stable because few firms (57 in our sample) have such episodes. ML equals the book value of debt divided by sum of the book value of debt and the market value of common stock. BL equals debt divided by the book value of total assets. Cash/TA equals total cash plus marketable securities divided by total assets. Net debt/TA equals BL minus Cash/TA.

\section{A. Time-series ranges over full time in sample}

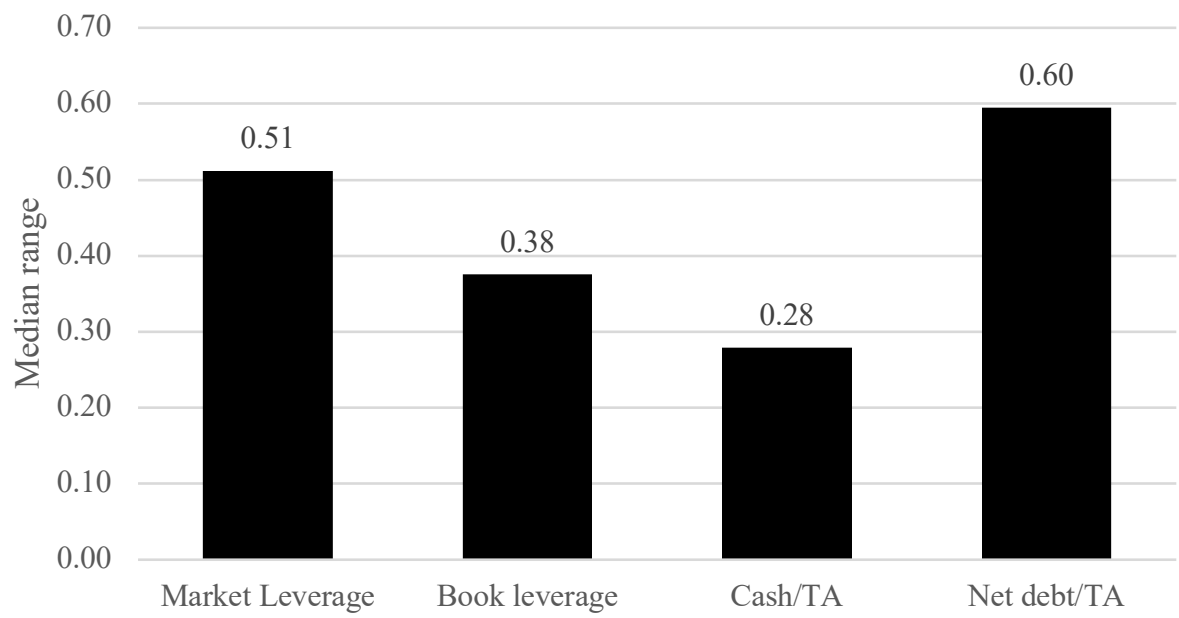

B. Time-series ranges during stable leverage or stable cash episodes

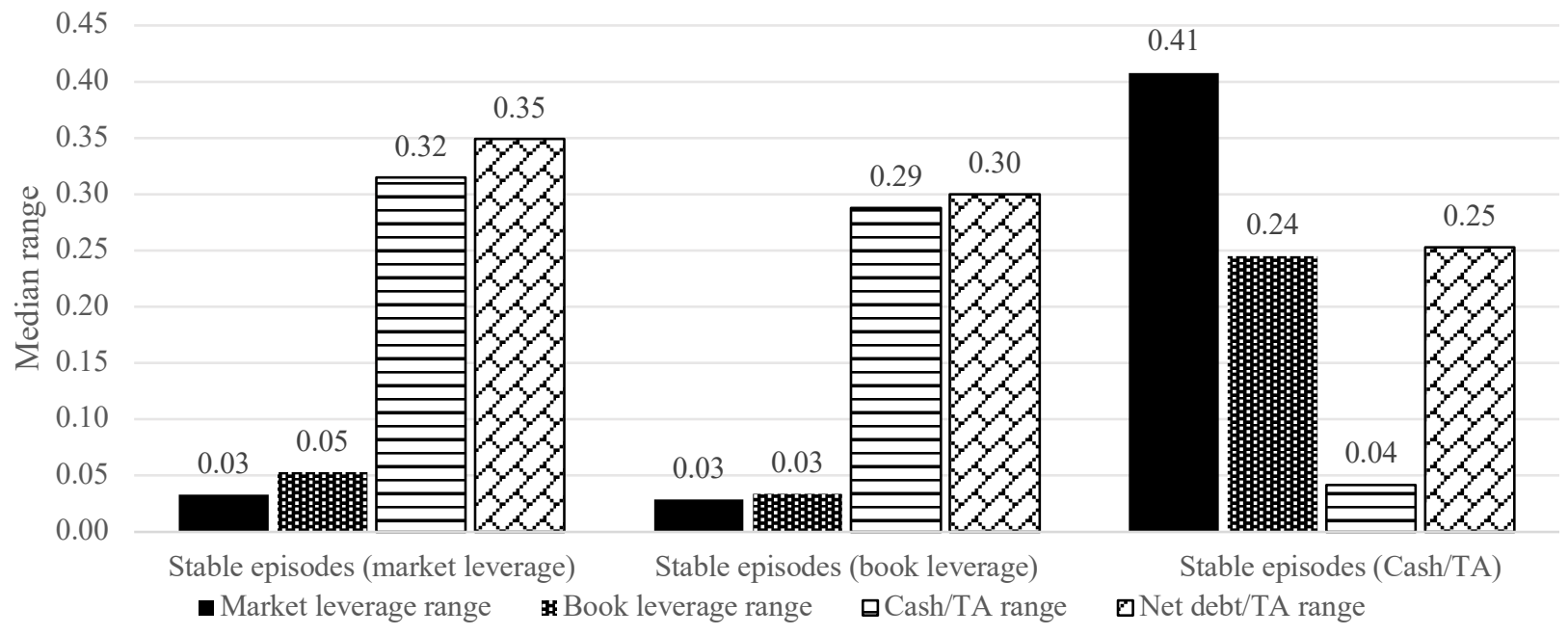


Figure 2

Time-Series Standard Deviations of Market-Leverage and Cash-Balance Ratios: Sample Sorted into Decile-Based Groups by the Median Time-Series Level of the Net-Debt Ratio

The sample contains 3,099 nonfinancial firms with at least 20 consecutive years of non-missing values on Compustat of total book assets, the market value of common stock, and holdings of cash and marketable securities. The sample is sorted into 10 groups based on the decile rank of each firm's time-series median of its net-debt ratio over its full time in the sample. Market leverage (ML) is the book value of debt divided by sum of the book value of debt and the market value of common stock. The cash-balance ratio (Cash/TA) is cash plus marketable securities divided by total assets. The net-debt ratio (Net debt/TA) is debt minus cash plus marketable securities, divided by total assets.

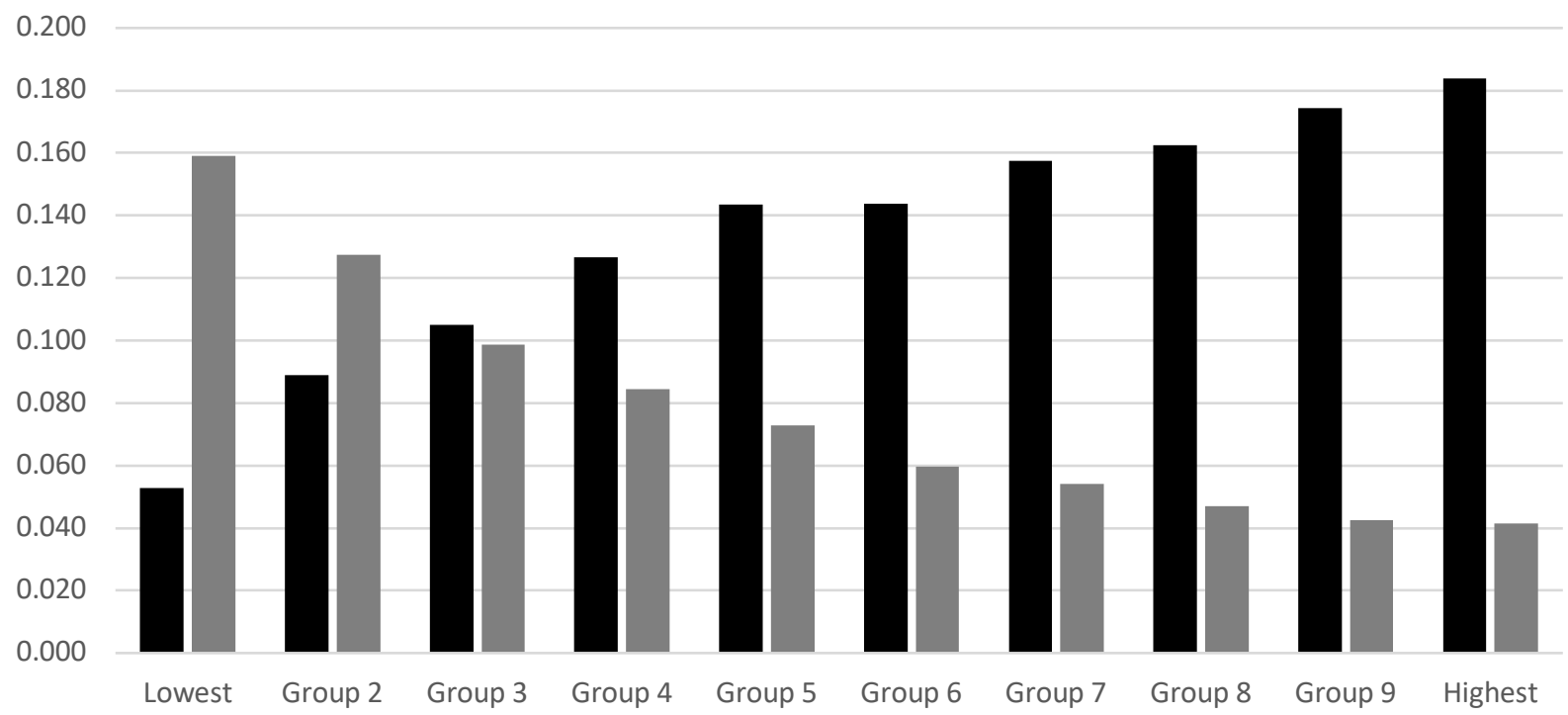

- Std dev of ML for median firm in decile-based group — Std dev of Cash/TA for median firm in decile-based group 
Figure 3

\section{Time-Series Median Levels of Leverage and Cash-Balance Ratios: Sample of Firms Listed at Least 20 Years Sorted into Decile-Based Groups}

Market leverage (ML) is the book value of debt divided by sum of the book value of debt and the market value of common stock. Book leverage (BL) is the book value of debt divided by the book value of total assets. The cashbalance ratio (Cash/TA) is cash plus marketable securities divided by total assets. The net-debt ratio (Net debt/TA) is debt minus cash plus marketable securities, divided by total assets, and equals BL minus Cash/TA. The sample contains 3,099 nonfinancial firms with at least 20 consecutive years of non-missing values on Compustat of total book assets, the market value of common stock, and holdings of cash and marketable securities. For each of the four ratios taken separately, the sample is sorted into 10 equal-sized groups based on the decile rank of each firm's time-series median of the ratio in question over that firm's full time in the sample. The far-left entry in the figure gives the medians across all 3,099 firms of the time-series medians of ML, BL, Cash/TA, and Net debt/TA.

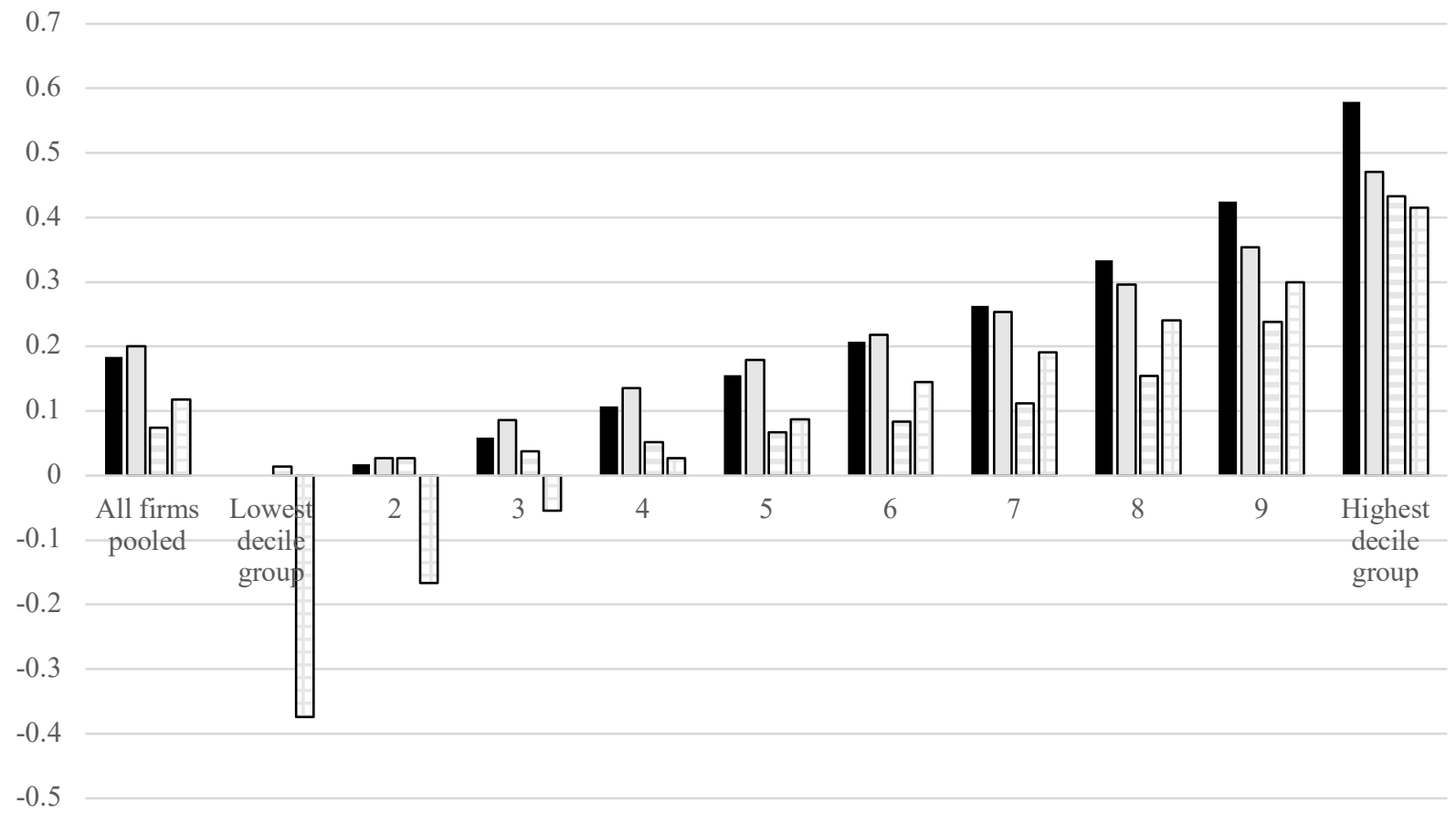

-ML aBL qCash/TA aNet debt/TA 


\section{Figure 4}

\section{Extent of Instability in the Leverage and Cash-Balance Cross-Sections}

The average R-squares plotted in the figure gauge the extent to which high (or low) values of the market-leverage (ML), book-leverage (BL), cash-balance (Cash/TA), and net-debt (Net debt/TA) ratios in a given year's cross-section correspond to high (or low) values in future cross-sections for the same ratio. For all ratios, the general approach here follows the analysis of BL reported by DeAngelo and Roll (2015, figure 3). The horizontal axis plots the number of years between pairs of cross sections of a given variable. The vertical axis plots the average R-square from a set of linear regressions of the later value of a given variable on a constant and the earlier value of the same variable. For example, to obtain the average R-square for cross sections of ML separated by one year, we first identify all firms in our full sample with ML data in 1950 and 1951, and obtain the R-square from regressing ML in 1951 on a constant and ML in 1950. We do the same for the years 1951 and 1952 taken as a pair and repeat this process for successive pairs of years, ending with 2015 and 2016. The first entry in the figure is the average R-square over all such regressions with cross sections that differ by exactly one year. To obtain the average R-square for a T-year difference in cross sections, we follow the same procedure using as regression inputs ML values for 1950 and 1950+T, 1951 and 1951+T, etc. We use the same algorithm to obtain the average R-squares for pairs of cross sections of BL, Cash/TA, and Net debt/TA. Market leverage (ML) equals the book value of debt divided by sum of the book value of debt and the market value of common stock. Book leverage equals the book value of debt divided by the book value of total assets. The cash-balance ratio (Cash/TA) equals total cash plus marketable securities divided by total assets. The net-debt ratio (Net debt/TA) equals BL minus Cash/TA.

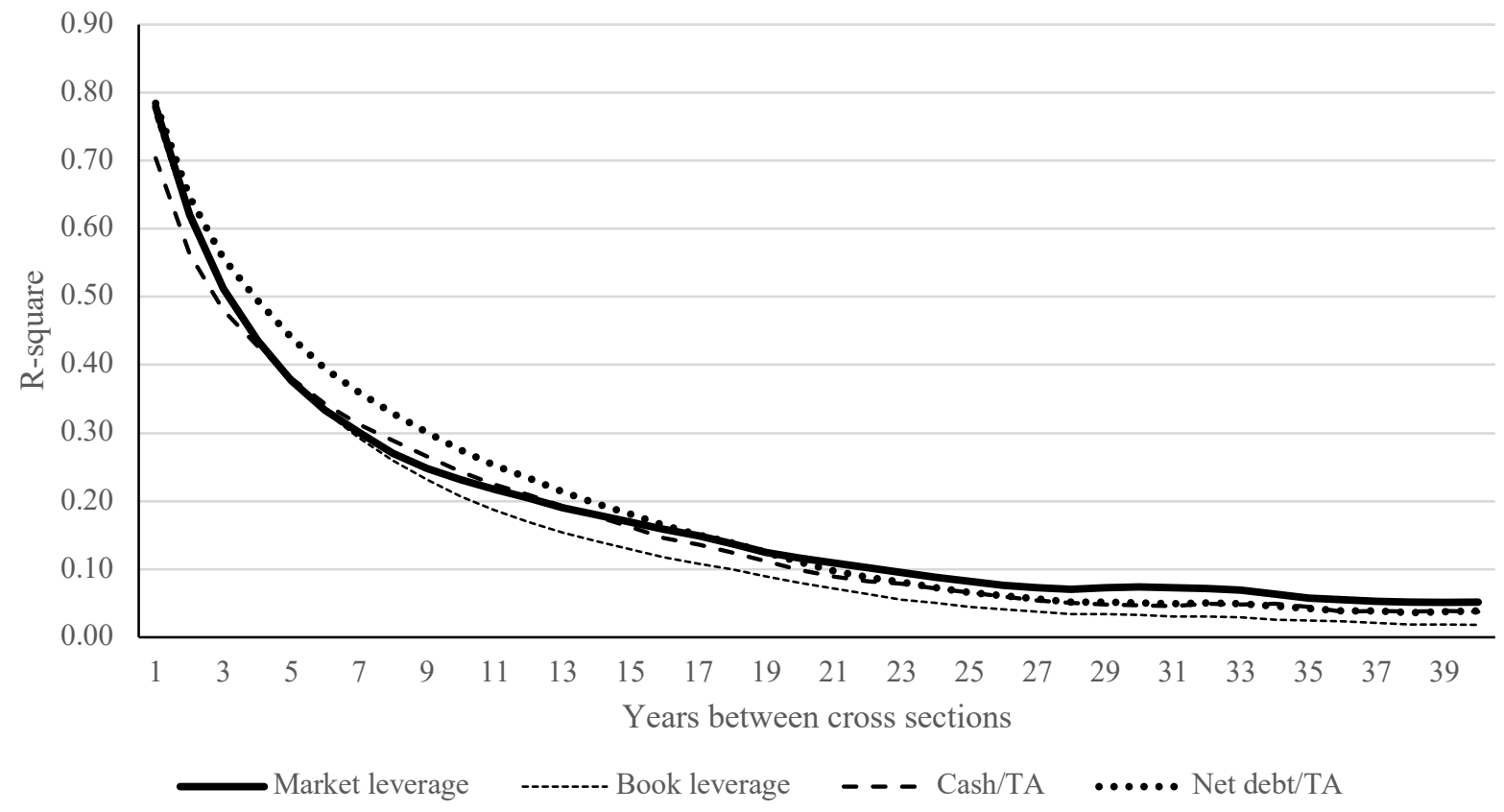




\section{Figure 5}

\section{Incidence of Episodes in which Firms Would Have Run Out of Cash or Had Positive Cash Balances If No External Funds Were Raised as Cash/TA Declines from Peak to Trough}

The cash-balance ratio (Cash/TA) equals cash plus marketable securities divided by the book value of total assets. Peak Cash/TA is the highest value of the ratio over a firm's time in the sample, while the trough is the lowest value over the 10 years that follow the firm's peak. The episode incidences plotted on the y-axis are based on our full sample and represent the frequency distribution of the hypothetical cash-balance (Cash/TA) ratios that firms would have had if they had not raised external funds while moving from peak Cash/TA to later trough. These frequency distributions correspond to the variables whose median values are reported in row 3 of Table 5. Negative hypothetical Cash/TA ratios are infeasible, and their high incidence in this figure indicate that many firms would have run out of cash if they had not raised outside funds. Full-sample results are given by the first column (solid-black fill) while the next two columns give the frequency counts for firms that raised some debt (angled-line fill) and raised only equity (dottedgrey fill).

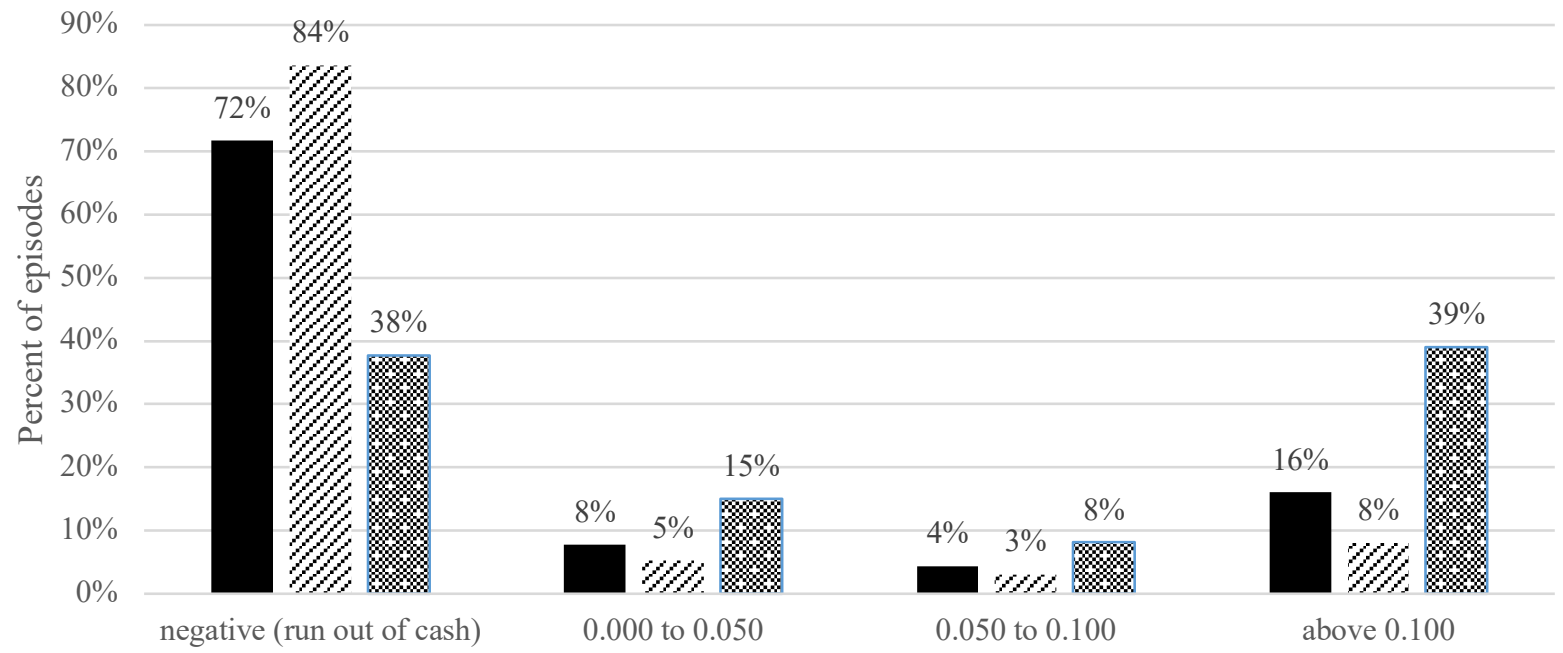

Hypothetical Cash/TA ratio assuming the firm does not raise external funds

- All firms $>$ Some debt issuance $\quad$ Only equity issuance 
Figure 6

\section{Asymmetric Incidence of Cash-Balance Squeezes: Levering-up versus Deleveraging Episodes}

For the median firm in our full sample, panel A plots the amount of external financing as a percent of cash balances at the end of its levering-up or deleveraging episode. For the median firm, panel B plots the hypothetical Cash/TA ratio that would have prevailed at the end of the episode absent external funding. Panel $\mathrm{C}$ plots the percent of firms that would have run out of cash without raising external funds for both levering-up and deleveraging episodes. Levering-up episodes are defined as in Table 6. Deleveraging episodes are defined symmetrically: We take each firm's historical peak level of leverage and track forward to the lowest level attained over the next 10 years.

\section{A. Median firm's external funding as a percent of cash balances at end of episode}

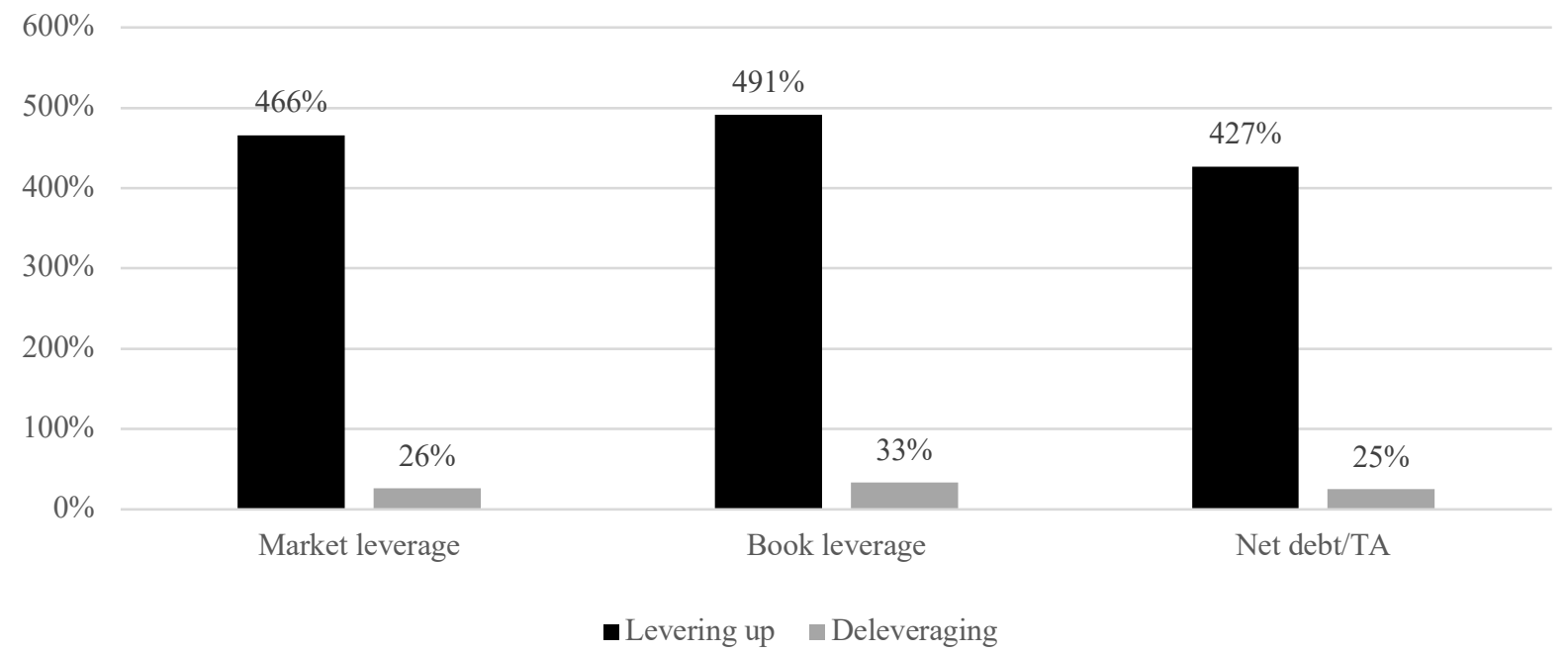

B. Median firm's hypothetical Cash/TA ratio absent external funding

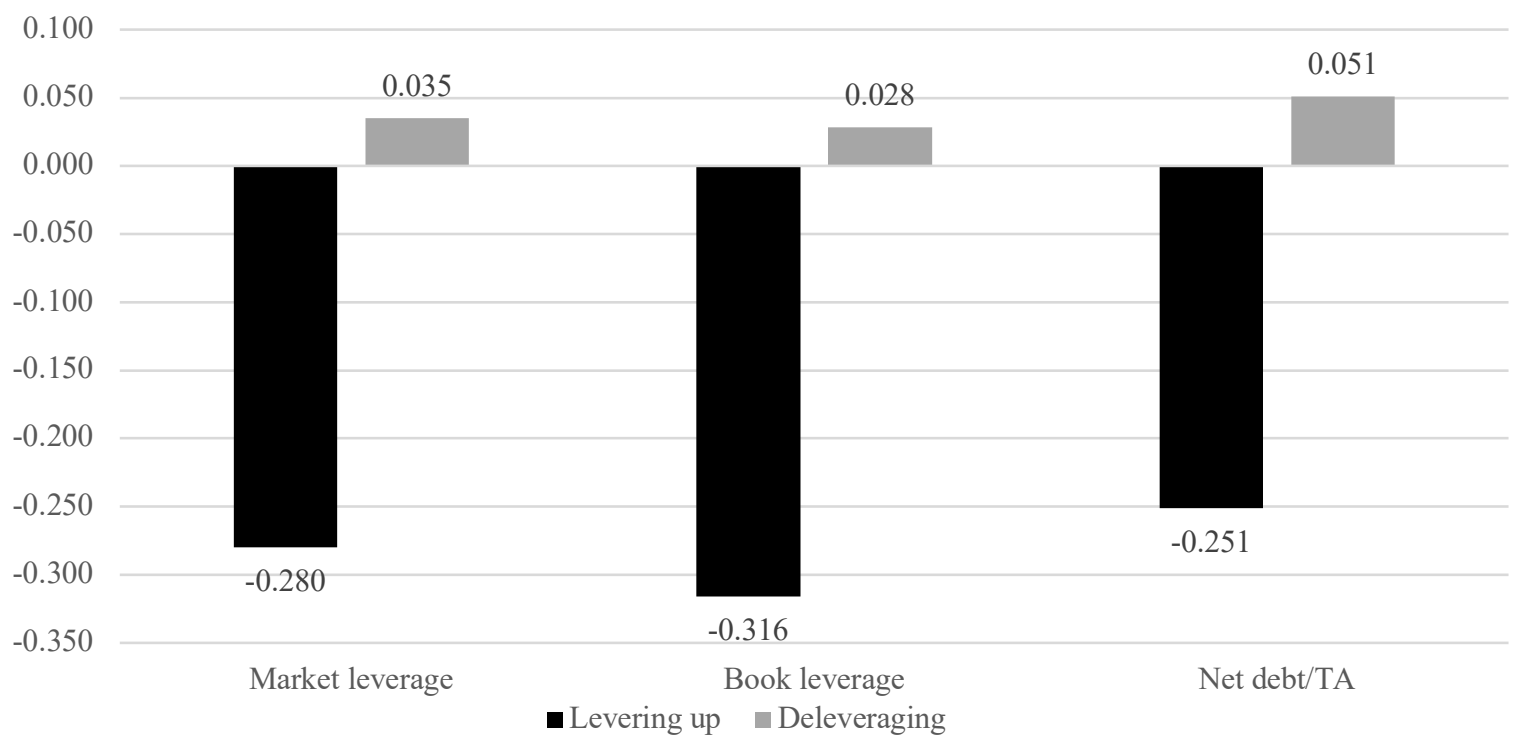

(figure continued) 
C. Percent of firms that would have run out of cash without external funding

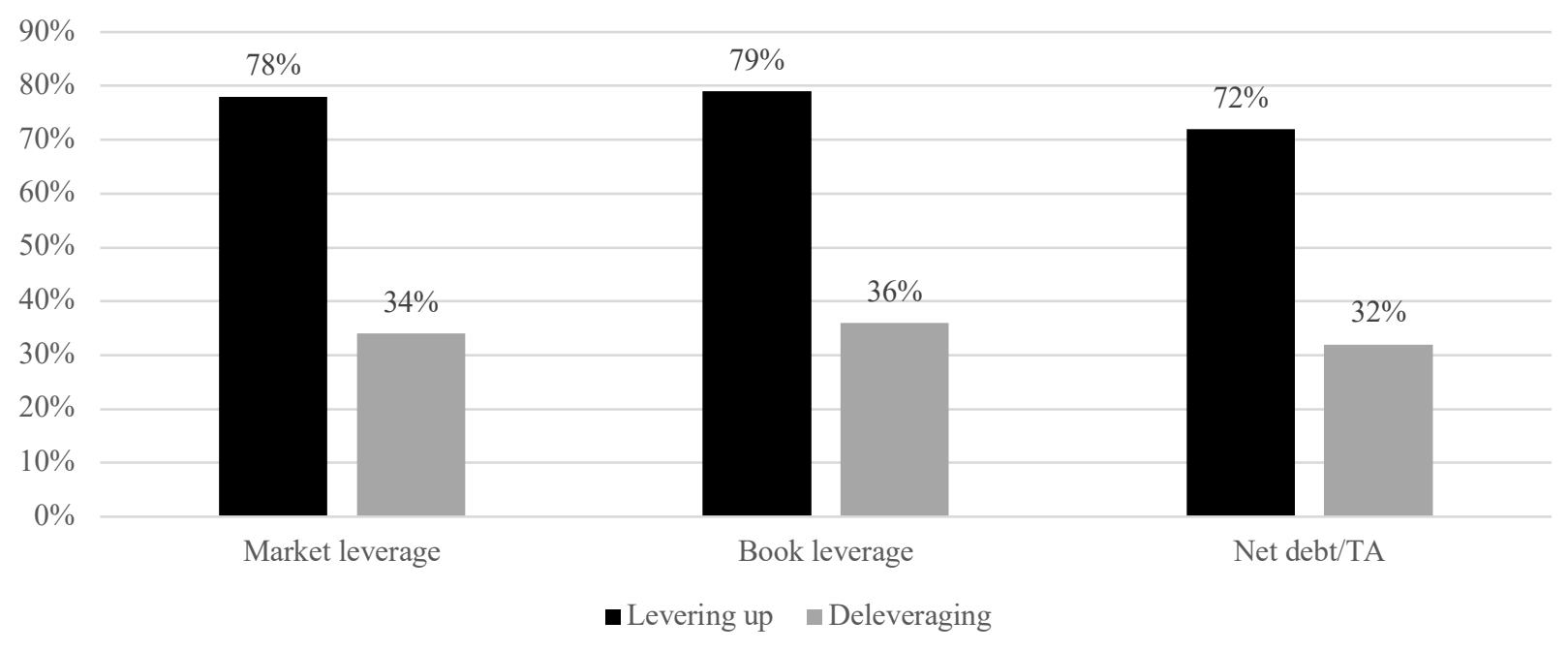


Table 1

Leverage and Cash-Balance Ratios: Time-Series Variation and Levels

The table reports the time-series standard deviation $(\sigma)$ and range of market leverage $(\mathrm{ML})$, book leverage (BL), the cash-balance ratio $(\mathrm{Cash} / \mathrm{TA})$, and the net-debt ratio (Net debt/TA) for the median firm in the sample. The sample contains 3,099 nonfinancial firms with at least 20 consecutive years of non-missing values of total book assets, the market value of common stock, and holdings of cash and marketable securities. In Panel A, the first column of numbers reports the median firm's $\sigma$ and range of each ratio using only the first two annual observations for each firm. The next column labeled reports the median $\sigma$ and range using the first five annual observations for each firm, while the next two columns report the values of the same variables conditional on using the first 10 or 20 years of data. The far-right column reports the same variables based on all data for all firms. Panel B reports the full cross-sectional distribution of the "all years" standard deviations whose medians are given in the last column of Panel A. Panel C reports the time-series median levels of ML, BL, Cash/TA, and Net debt/TA for 10 groups ranked on the standard deviation of the ratio in question (as with panel B). ML is the book value of debt divided by sum of the book value of debt and the market value of common stock. BL is debt divided by the book value of total assets. Cash/TA is total cash plus marketable securities divided by total assets. Net debt/TA is BL minus Cash/TA.

\section{A. Standard Deviations and Ranges: Attenuated Versus Long Measurement Horizons}

\begin{tabular}{|c|c|c|c|c|c|}
\hline \multirow{3}{*}{ Time-series standard deviation $(\sigma)$} & \multicolumn{5}{|c|}{ Median value conditional on specified number of years of data: } \\
\hline & 2 & 5 & 10 & 20 & All \\
\hline & & & & & \\
\hline 1. Market leverage (ML) & 0.030 & 0.063 & 0.092 & 0.121 & 0.137 \\
\hline 2. Book leverage $(\mathrm{BL})$ & 0.019 & 0.047 & 0.068 & 0.092 & 0.105 \\
\hline 3. Cash-balance ratio (Cash/TA) & 0.016 & 0.036 & 0.050 & 0.063 & 0.073 \\
\hline 4. Net-debt ratio (Net debt/TA) & 0.035 & 0.074 & 0.101 & 0.133 & 0.154 \\
\hline Time-series range & & & & & \\
\hline 5. Market leverage (ML) & 0.042 & 0.154 & 0.278 & 0.425 & 0.512 \\
\hline 6. Book leverage (BL) & 0.027 & 0.114 & 0.202 & 0.310 & 0.375 \\
\hline 7. Cash-balance ratio (Cash/TA) & 0.022 & 0.086 & 0.148 & 0.222 & 0.279 \\
\hline 8. Net-debt ratio (Net debt/TA) & 0.049 & 0.181 & 0.309 & 0.473 & 0.595 \\
\hline
\end{tabular}

\section{B. Cross-Firm Distributions of the Standard Deviations of Leverage and Cash-Balance Ratios}

\begin{tabular}{|c|c|c|c|c|c|c|c|c|c|c|c|}
\hline \multirow[b]{3}{*}{ Standard deviation $(\sigma)$ for median firm: } & \multicolumn{10}{|c|}{ Sample sorted into 10 groups according to each firm's $\sigma$ of ML, BL, Cash/TA or Net debt/TA } & \multirow{2}{*}{$\begin{array}{c}\text { Ratio of } \\
\text { Highest to } \\
\text { Lowest }\end{array}$} \\
\hline & $\begin{array}{l}\text { Lowest } \\
\sigma \text { group }\end{array}$ & $\begin{array}{c}\text { Group } \\
2\end{array}$ & $\begin{array}{c}\text { Group } \\
3\end{array}$ & $\begin{array}{c}\text { Group } \\
4\end{array}$ & $\begin{array}{c}\text { Group } \\
5\end{array}$ & $\begin{array}{c}\text { Group } \\
6\end{array}$ & $\begin{array}{c}\text { Group } \\
7\end{array}$ & $\begin{array}{c}\text { Group } \\
8\end{array}$ & $\begin{array}{c}\text { Group } \\
9\end{array}$ & $\begin{array}{l}\text { Highest } \\
\sigma \text { group }\end{array}$ & \\
\hline & 0.031 & 0.068 & 0.089 & 0.109 & 0.128 & 0.146 & 0.166 & 0.189 & 0.215 & 0.257 & 8.3 \\
\hline 2. Book leverage (BL) & 0.038 & 0.060 & 0.074 & 0.086 & 0.099 & 0.112 & 0.126 & 0.145 & 0.173 & 0.232 & 6.1 \\
\hline 3. Cash-balance ratio (Cash/TA) & 0.020 & 0.034 & 0.045 & 0.056 & 0.067 & 0.080 & 0.098 & 0.118 & 0.150 & 0.205 & 10.3 \\
\hline 4. Net-debt ratio (Net debt/TA) & 0.069 & 0.093 & 0.112 & 0.128 & 0.146 & 0.164 & 0.186 & 0.213 & 0.252 & 0.319 & 4.6 \\
\hline
\end{tabular}

(table continued) 


\section{Median Time-Series Leverage and Cash-Balance Ratios: Sample Sorted by Standard Deviation ( $\sigma$ ) of the Specified Ratio}

\begin{tabular}{|c|c|c|c|c|c|c|c|c|c|c|c|}
\hline \multicolumn{12}{|c|}{ Sample sorted into 10 groups according to each firm's $\sigma$ of ML, BL, Cash/TA or Net debt/TA } \\
\hline & $\begin{array}{l}\text { Lowest } \\
\sigma \text { group }\end{array}$ & $\begin{array}{c}\text { Group } \\
2\end{array}$ & $\begin{array}{c}\text { Group } \\
3\end{array}$ & $\begin{array}{c}\text { Group } \\
4\end{array}$ & $\begin{array}{c}\text { Group } \\
5\end{array}$ & $\begin{array}{c}\text { Group } \\
6\end{array}$ & $\begin{array}{c}\text { Group } \\
7\end{array}$ & $\begin{array}{c}\text { Group } \\
8\end{array}$ & $\begin{array}{c}\text { Group } \\
9\end{array}$ & $\begin{array}{l}\text { Highest } \\
\sigma \text { group }\end{array}$ & $\begin{array}{c}\text { All firms } \\
\text { pooled }\end{array}$ \\
\hline \multicolumn{12}{|c|}{ Time-series median level of specified ratio for median firm in group: } \\
\hline 1. Market leverage (ML) & 0.001 & 0.063 & 0.107 & 0.163 & 0.179 & 0.221 & 0.252 & 0.310 & 0.297 & 0.340 & 0.184 \\
\hline 2. Book leverage (BL) & 0.013 & 0.163 & 0.199 & 0.191 & 0.194 & 0.217 & 0.222 & 0.217 & 0.241 & 0.257 & 0.201 \\
\hline 3. Cash-balance ratio (Cash/TA) & 0.023 & 0.038 & 0.049 & 0.060 & 0.070 & 0.084 & 0.114 & 0.163 & 0.207 & 0.282 & 0.074 \\
\hline 4. Net-debt ratio (Net debt/TA) & 0.208 & 0.167 & 0.157 & 0.137 & 0.117 & 0.099 & 0.094 & 0.070 & 0.047 & -0.039 & 0.118 \\
\hline
\end{tabular}




\section{Table 2}

Time-Series Variation in Leverage and Cash-Balance Ratios:

\section{Sample Sorted into Decile-Based Groups by the Median Time-Series Level of the Net-Debt Ratio}

The sample contains 3,099 nonfinancial firms with at least 20 consecutive years of non-missing values on Compustat of total book assets, the market value of common stock, and holdings of cash and marketable securities. The sample is sorted into 10 groups based on the decile rank of each firm's time-series median of its net-debt ratio over its full time in the sample. Market leverage (ML) is the book value of debt divided by sum of the book value of debt and the market value of common stock. The cash-balance ratio (Cash/TA) is cash plus marketable securities divided by total assets. The net-debt ratio (Net debt/TA) is debt minus cash plus marketable securities, divided by total assets.

\begin{tabular}{|c|c|c|c|c|c|c|c|c|c|c|c|}
\hline \multirow[b]{2}{*}{ Value for median firm of } & \multicolumn{10}{|c|}{ Firms sorted into decile-based groups according to time-series median level of Net debt/TA ratio: } & \multirow{2}{*}{$\begin{array}{c}\text { All } \\
\text { firms } \\
\text { pooled }\end{array}$} \\
\hline & $\begin{array}{c}\text { Lowest } \\
10 \%\end{array}$ & $\begin{array}{c}\text { Group } \\
2\end{array}$ & $\begin{array}{c}\text { Group } \\
\mathbf{3}\end{array}$ & $\begin{array}{c}\text { Group } \\
4\end{array}$ & $\begin{array}{c}\text { Group } \\
5\end{array}$ & $\begin{array}{c}\text { Group } \\
6\end{array}$ & $\begin{array}{c}\text { Group } \\
7\end{array}$ & $\begin{array}{c}\text { Group } \\
8\end{array}$ & $\begin{array}{c}\text { Group } \\
9\end{array}$ & $\begin{array}{c}\text { Highest } \\
10 \%\end{array}$ & \\
\hline 1. Time-series median Net debt/TA & -0.374 & -0.167 & -0.054 & 0.027 & 0.087 & 0.145 & 0.191 & 0.240 & 0.299 & 0.415 & 0.118 \\
\hline 2. Time-series median ML & 0.000 & 0.017 & 0.052 & 0.103 & 0.171 & 0.215 & 0.263 & 0.315 & 0.390 & 0.521 & 0.184 \\
\hline 3. Time-series median Cash/TA & 0.419 & 0.222 & 0.137 & 0.096 & 0.074 & 0.057 & 0.049 & 0.038 & 0.034 & 0.034 & 0.074 \\
\hline 4. Standard deviation of Net debt/TA & 0.203 & 0.188 & 0.169 & 0.154 & 0.148 & 0.139 & 0.136 & 0.129 & 0.141 & 0.150 & 0.154 \\
\hline 5. Standard deviation of ML & 0.053 & 0.089 & 0.105 & 0.127 & 0.144 & 0.144 & 0.158 & 0.162 & 0.174 & 0.184 & 0.137 \\
\hline 6. Standard deviation of Cash/TA & 0.159 & 0.127 & 0.099 & 0.084 & 0.073 & 0.060 & 0.054 & 0.047 & 0.043 & 0.041 & 0.073 \\
\hline 7. Time-series minimum Net debt/TA & -0.729 & -0.476 & -0.340 & -0.263 & -0.206 & -0.142 & -0.103 & -0.040 & 0.026 & 0.122 & -0.219 \\
\hline 8. Time-series maximum Net debt/TA & 0.040 & 0.186 & 0.267 & 0.300 & 0.340 & 0.377 & 0.422 & 0.448 & 0.518 & 0.646 & 0.390 \\
\hline 9. Time-series minimum ML & 0.000 & 0.000 & 0.000 & 0.000 & 0.005 & 0.016 & 0.037 & 0.066 & 0.100 & 0.138 & 0.003 \\
\hline 10. Time-series maximum ML & 0.189 & 0.320 & 0.387 & 0.486 & 0.557 & 0.581 & 0.645 & 0.694 & 0.775 & 0.858 & 0.569 \\
\hline 11. Time-series minimum Cash/TA & 0.128 & 0.034 & 0.018 & 0.012 & 0.011 & 0.008 & 0.006 & 0.006 & 0.005 & 0.005 & 0.011 \\
\hline 12. Time-series maximum Cash/TA & 0.747 & 0.496 & 0.383 & 0.323 & 0.284 & 0.245 & 0.224 & 0.198 & 0.184 & 0.177 & 0.296 \\
\hline
\end{tabular}


Table 3

\section{Leverage and Cash-Balance Interactions: Time-Series Levels and Volatilities}

The sample contains 3,099 nonfinancial firms with at least 20 consecutive years of non-missing values of total book assets, the market value of common stock, and holdings of cash and marketable securities. Columns (1) and (2) analyze the subsamples of firms with the lowest $10 \%$ and highest $10 \%$ time-series median levels of the ratio specified in the labels for panels A to C. Columns (3) and (4) analyze the subsamples of firms with the lowest and highest 10\% time-series standard deviations $(\sigma)$ of the ratio specified in the panel labels. The numbers in the body of the table equal the cross-firm medians of the statistic in question. Market leverage (ML) equals the book value of debt divided by sum of the book value of debt and the market value of common stock. Book leverage (BL) equals the book value of debt divided by the book value of total assets. The cash-balance ratio (Cash/TA) equals total cash plus marketable securities divided by total assets. Tables IA1 and IA2 in the Internet Appendix report the full cross-section of results for both partitions reported in this table, i.e., they include these data plus the analogous statistics for the eight groups that comprise the middle $80 \%$ of all observations.

\begin{tabular}{lcccc}
\hline $\begin{array}{l}\text { Values for the median firm in the } \\
\text { specified (lowest versus highest) } \\
\text { sample sorting: }\end{array}$ & $\begin{array}{c}\text { Median time-series level sort: } \\
\text { Lowest } 10 \%\end{array}$ & $\begin{array}{c}\text { Highest } 10 \% \\
(1)\end{array}$ & $\begin{array}{c}\text { Standard deviation sort: } \\
\text { Lowest } 10 \%\end{array}$ & $\begin{array}{c}\text { Highest } 10 \% \\
(4)\end{array}$ \\
\hline $\begin{array}{l}\text { A. Market leverage (ML) sorting } \\
\text { 1. } \sigma(\mathrm{ML})\end{array}$ & 0.046 & 0.187 & 0.031 & 0.257 \\
2. $\sigma(\mathrm{Cash} / \mathrm{TA})$ & 0.141 & 0.049 & 0.116 & 0.075 \\
& & & & \\
3. Time-series median ML & 0.000 & 0.579 & 0.001 & 0.340 \\
4. Time-series median Cash/TA & 0.323 & 0.048 & 0.279 & 0.062 \\
& & & & \\
B. Book leverage (BL) sorting & & & & \\
5. $\sigma(\mathrm{BL})$ & 0.057 & 0.142 & 0.038 & 0.232 \\
6. $\sigma($ Cash/TA) & 0.141 & 0.052 & 0.089 & 0.111 \\
& & & & \\
7. Time-series median BL & 0.000 & 0.470 & 0.013 & 0.257 \\
8. Time-series median Cash/TA & 0.312 & 0.046 & 0.189 & 0.091 \\
& & & & \\
C. Cash-balance ratio (Cash/TA) sorting & & & & 0.205 \\
9. $\sigma($ Cash/TA) & 0.029 & 0.163 & 0.020 & 0.108 \\
10. $\sigma(\mathrm{ML})$ & 0.154 & 0.064 & 0.142 & 0.133 \\
11. $\sigma(\mathrm{BL})$ & 0.109 & 0.094 & 0.090 & 0.282 \\
12. Time-series median Cash/TA & & & & 0.024 \\
13. Time-series median ML & 0.014 & 0.433 & 0.023 & 0.046 \\
14. Time-series median BL & 0.318 & 0.002 & 0.352 & \\
\hline
\end{tabular}


Table 4

\section{Stable Leverage and Cash-Balance Episodes}

The table reports summary statistics on the time-series standard deviation $(\sigma)$, range, and level of market leverage (ML), book leverage (BL), the cash-balance ratio (Cash/TA), and the net-debt ratio (Net debt/TA) for subsamples of the 3,099 firms with at least 20 years of non-missing data. We first identify the subset of firms that have episodes of at least 10 consecutive years in which a given ratio (ML, BL, Cash/TA, or Net debt/TA) remains in a bandwidth of 0.050 . For each firm so identified, we take the longest such stable episode and report summary statistics in the first four columns of the table. In the remaining columns, we consider all firms that have episodes of at least 10 consecutive years for which Cash/TA (first two columns) or ML (next two columns) either fall below 0.050 or never fall below 0.300 . We include at most one episode per firm (and take only the longest when a firm has more than one relevant episode). ML equals the book value of debt divided by sum of the book value of debt and the market value of common stock. BL equals debt divided by the book value of total assets. Cash/TA equals total cash plus marketable securities divided by total assets. Net debt/TA equals BL minus Cash/TA.

\begin{tabular}{|c|c|c|c|c|c|c|c|c|}
\hline & \multicolumn{4}{|c|}{ Episodes with ratio remaining in 0.050 bandwidth: } & \multicolumn{4}{|c|}{ Episodes with consistently low or consistently high ratios } \\
\hline & \multirow{2}{*}{$\begin{array}{c}\text { Market } \\
\text { Leverage }\end{array}$} & \multirow{2}{*}{$\begin{array}{c}\text { Book } \\
\text { leverage }\end{array}$} & \multirow{2}{*}{$\begin{array}{l}\text { Cash-balance } \\
\text { ratio }\end{array}$} & \multirow{2}{*}{$\begin{array}{l}\text { Net-debt } \\
\text { ratio }\end{array}$} & \multicolumn{2}{|c|}{ Cash/TA during episode } & \multicolumn{2}{|c|}{ ML during episode } \\
\hline & & & & & $<0.050$ & $\geq 0.300$ & $<0.050$ & $\geq 0.300$ \\
\hline 1. Number of firms & 781 & 758 & 1,267 & 57 & 867 & 290 & 707 & 863 \\
\hline Percent of sample & $25.2 \%$ & $24.5 \%$ & $40.9 \%$ & $1.8 \%$ & $28.0 \%$ & $9.4 \%$ & $22.8 \%$ & $27.8 \%$ \\
\hline Median number of years in episode & 15 & 14 & 14 & 11 & 14 & 15 & 15 & 15 \\
\hline $\begin{array}{l}\text { 2. Median firm's value (during episode) of: } \\
\sigma(\mathrm{ML})\end{array}$ & 0.010 & 0.008 & 0.121 & 0.046 & 0.123 & 0.027 & 0.009 & 0.123 \\
\hline$\sigma(\mathrm{BL})$ & 0.016 & 0.011 & 0.074 & 0.016 & 0.078 & 0.044 & 0.015 & 0.075 \\
\hline$\sigma(\mathrm{Cash} / \mathrm{TA})$ & 0.093 & 0.084 & 0.012 & 0.013 & 0.010 & 0.113 & 0.099 & 0.030 \\
\hline$\sigma($ Net debt/TA $)$ & 0.102 & 0.087 & 0.076 & 0.015 & 0.080 & 0.137 & 0.106 & 0.086 \\
\hline range(ML) & 0.033 & 0.029 & 0.408 & 0.151 & 0.413 & 0.093 & 0.030 & 0.416 \\
\hline range(BL) & 0.053 & 0.034 & 0.245 & 0.050 & 0.261 & 0.139 & 0.049 & 0.255 \\
\hline range(Cash/TA) & 0.315 & 0.288 & 0.042 & 0.039 & 0.034 & 0.373 & 0.334 & 0.106 \\
\hline range(Net debt/TA) & 0.349 & 0.300 & 0.253 & 0.045 & 0.269 & 0.452 & 0.363 & 0.300 \\
\hline time-series median ML & 0.000 & 0.000 & 0.328 & 0.192 & 0.340 & 0.000 & 0.000 & 0.545 \\
\hline time-series median BL & 0.000 & 0.000 & 0.286 & 0.204 & 0.303 & 0.000 & 0.000 & 0.388 \\
\hline time-series median Cash/TA & 0.261 & 0.233 & 0.023 & 0.051 & 0.015 & 0.550 & 0.277 & 0.038 \\
\hline time-series median Net debt/TA & -0.240 & -0.223 & 0.259 & 0.159 & 0.287 & -0.495 & -0.265 & 0.337 \\
\hline $\begin{array}{l}\text { 3. Median firm's \% of years in episode with } \\
\text { negative net debt } \\
\text { zero debt }\end{array}$ & $\begin{array}{c}100.0 \% \\
54.2 \% \\
\end{array}$ & $\begin{array}{c}100.0 \% \\
54.8 \% \\
\end{array}$ & $\begin{array}{l}0.0 \% \\
0.0 \% \\
\end{array}$ & $\begin{array}{l}0.0 \% \\
0.0 \% \\
\end{array}$ & $\begin{array}{l}0.0 \% \\
0.0 \% \\
\end{array}$ & $\begin{array}{c}100.0 \% \\
50.0 \% \\
\end{array}$ & $\begin{array}{c}100.0 \% \\
60.0 \% \\
\end{array}$ & $\begin{array}{l}0.0 \% \\
0.0 \% \\
\end{array}$ \\
\hline
\end{tabular}


Table 5

Cash Squeezes and Contemporaneous Leverage Increases

The cash-balance ratio (Cash/TA) equals cash plus marketable securities divided by the book value of total assets. Peak Cash/TA is the highest value of the ratio over a firm's time in the sample, while the trough is the lowest value over the 10 years that follow the firm's peak. Market leverage (ML) is the book value of debt divided by the sum of the book value of debt and the market value of equity. The second column considers the subset of firms that would have run out of cash had they not raised outside funds during the period from peak Cash/TA to trough. The third column considers firms that would have had positive cash balances at the trough even without raising funds. Row 3 reports the Cash/TA ratio a firm would hypothetically have if it did not raise external funds between peak Cash/TA and the later trough. It gauges the extent to which cash balances are squeezed during the time from peak Cash/TA to trough. It assumes that, aside from external financing over the time from peak to trough, everything else (earnings, investment, etc.) remains the same, and that the firm's cash balances and assets are reduced by the amount of the proceeds from issuing debt and equity. Note that some hypothetical Cash/TA ratios may not be feasible choices because a firm cannot operate with negative cash balances. The variable in row 3 is the basis for the sample partitioning in the second and third columns. [In row 8 , the number of firms for the column partitions do not sum to that for the full sample because of missing data.] The Appendix contains the Compustat formulas for these issuance variables and for the hypothetical Cash/TA ratio.

\begin{tabular}{|c|c|c|c|c|c|c|c|}
\hline \multirow{3}{*}{ Median value (except rows 8 and 9) } & \multirow{3}{*}{$\begin{array}{c}\text { All } \\
\text { firms } \\
\text { pooled }\end{array}$} & \multirow{2}{*}{\multicolumn{2}{|c|}{$\begin{array}{l}\text { Would run out of cash } \\
\text { without external funds? }\end{array}$}} & \multicolumn{4}{|c|}{ Debt proceeds as a $\%$ of total external funds raised $(\delta):$} \\
\hline & & & & \multirow{2}{*}{$\begin{array}{c}\delta=100 \% \\
\text { all debt }\end{array}$} & \multirow{2}{*}{$\begin{array}{l}50 \%<\delta<100 \% \\
\text { issue mostly debt }\end{array}$} & \multirow{2}{*}{$\begin{array}{c}0 \%<\delta \leq 50 \% \\
\text { issue some debt }\end{array}$} & \multirow{2}{*}{$\begin{array}{c}\delta=0 \% \\
\text { all equity }\end{array}$} \\
\hline & & yes & no & & & & \\
\hline A. Full sample & & & & & & & \\
\hline 1. Cash/TA at peak & 0.298 & 0.255 & 0.400 & 0.185 & 0.238 & 0.523 & 0.480 \\
\hline 2. Cash/TA at later trough & 0.044 & 0.024 & 0.161 & 0.029 & 0.023 & 0.071 & 0.152 \\
\hline 3. Cash/TA at trough w/o external financing & -0.110 & -0.357 & 0.117 & -0.088 & -0.278 & -0.768 & 0.037 \\
\hline 4. External financing as a $\%$ of cash at trough & $290 \%$ & $1003 \%$ & $6 \%$ & $406 \%$ & $974 \%$ & $728 \%$ & $38 \%$ \\
\hline 5. Market leverage at peak Cash/TA & 0.055 & 0.066 & 0.033 & 0.130 & 0.085 & 0.008 & 0.023 \\
\hline 6. Market leverage at later trough & 0.206 & 0.283 & 0.046 & 0.349 & 0.340 & 0.103 & 0.006 \\
\hline 7. Number of years from peak to trough & 3 & 3 & 2 & 2 & 4 & 4 & 2 \\
\hline 8. Number of firms & 14,866 & 8,750 & 4,858 & 2,110 & 4,715 & 2,187 & 3,151 \\
\hline 9. Percent of sample & $100 \%$ & $64 \%$ & $36 \%$ & $17 \%$ & $39 \%$ & $18 \%$ & $26 \%$ \\
\hline B. Firms with at least 20 years of data & & & & & & & \\
\hline 1. Cash/TA at peak & 0.296 & 0.275 & 0.353 & 0.254 & 0.259 & 0.421 & 0.394 \\
\hline 2. Cash/TA at later trough & 0.042 & 0.025 & 0.135 & 0.043 & 0.023 & 0.058 & 0.121 \\
\hline 3. Cash/TA at trough w/o external financing & -0.126 & -0.281 & 0.097 & -0.086 & -0.252 & -0.473 & 0.055 \\
\hline 4. External financing as a $\%$ of cash at trough & $348 \%$ & $916 \%$ & $7 \%$ & $282 \%$ & $967 \%$ & $627 \%$ & $31 \%$ \\
\hline 5. Market leverage at peak Cash/TA & 0.073 & 0.083 & 0.051 & 0.075 & 0.096 & 0.014 & 0.068 \\
\hline 6. Market leverage at later trough & 0.191 & 0.245 & 0.045 & 0.226 & 0.292 & 0.103 & 0.016 \\
\hline 7. Number of years from peak to trough & 6 & 7 & 4 & 4 & 7 & 7 & 6 \\
\hline 8. Number of firms & 2,901 & 1,777 & 824 & 329 & 1,155 & 402 & 463 \\
\hline 9. Percent of sample & $100 \%$ & $68 \%$ & $32 \%$ & $14 \%$ & $49 \%$ & $17 \%$ & $20 \%$ \\
\hline
\end{tabular}


Table 6

Cash-Balance Squeezes When Firms Lever Up

The table examines firms from their historically lowest (trough) market leverage (ML) or net-debt ratio (Net debt/TA) to the highest (peak) subsequent value of that ratio over the next 10 years. For brevity, the table excludes the analysis of levering up in book leverage terms, which yields findings that are qualitatively identical to those for market leverage. Panel A examines the full sample, while panel B examines the sample of firms with at least 20 years of date. For inclusion in this analysis, a firm must have at least one year of data on Compustat after the trough level of ML or Net debt/TA. The cash-balance ratio (Cash/TA) equals cash plus marketable securities divided by the book value of total assets. The hypothetical Cash/TA ratios in row 3 assume that the absence of external financing implies a reduction in cash balances equal to the foregone issuance proceeds, while everything else (earnings, investment, etc.) remains the same; see the Appendix for the method we use to generate these numbers from Compustat. The negative hypothetical values in row 3 are not feasible choices. They are measures of the extent to which sample firms were facing a cash squeeze during their episodes of cash-balance drawdown or levering up. The leverage variable in rows 5 and 6 is the variable specified in the column header. NEED SENTENCE EXPLAINING WHY PARTITIONS DO NOT SUM TO TOTAL NUMBER OF FIRMS.

\begin{tabular}{|c|c|c|c|c|c|c|}
\hline \multirow[b]{3}{*}{ Median value (except rows 8 and 9) } & \multicolumn{3}{|c|}{ Market leverage (ML) } & \multicolumn{3}{|c|}{ Net-debt ratio (Net debt/TA) } \\
\hline & \multirow{2}{*}{$\begin{array}{c}\text { All firms } \\
\text { pooled }\end{array}$} & \multicolumn{2}{|c|}{ Would run out of cash? } & \multirow{2}{*}{$\begin{array}{c}\text { All firms } \\
\text { pooled }\end{array}$} & \multicolumn{2}{|c|}{ Would run out of cash? } \\
\hline & & yes & no & & yes & no \\
\hline C. Full sample & & & & & & \\
\hline 1. Cash/TA at leverage trough & 0.135 & 0.110 & 0.266 & 0.276 & 0.215 & 0.477 \\
\hline 2. Cash/TA at later leverage peak & 0.054 & 0.039 & 0.209 & 0.058 & 0.037 & 0.216 \\
\hline 3. Cash/TA at leverage peak w/o external financing & -0.280 & -0.451 & 0.124 & -0.251 & -0.505 & 0.159 \\
\hline 4. External financing as a $\%$ of cash at peak & $466 \%$ & $805 \%$ & $28 \%$ & $427 \%$ & $914 \%$ & $9 \%$ \\
\hline 5. ML or Net debt/TA at its trough & 0.030 & 0.035 & 0.012 & -0.196 & -0.121 & -0.433 \\
\hline 6. ML or Net debt/TA at its peak & 0.400 & 0.448 & 0.154 & 0.231 & 0.322 & -0.137 \\
\hline 7. Number of years from peak to trough & 3 & 3 & 1 & 3 & 4 & 2 \\
\hline 8. Number of firms & 13,088 & 9,289 & 2,663 & 14,964 & 9,816 & 3,850 \\
\hline 9. Percent of sample & $100 \%$ & $78 \%$ & $22 \%$ & $100 \%$ & $72 \%$ & $28 \%$ \\
\hline D. Firms with at least 20 years of data & & & & & & \\
\hline 1. Cash/TA at leverage trough & 0.124 & 0.110 & 0.236 & 0.271 & 0.234 & 0.419 \\
\hline 2. Cash/TA at later leverage peak & 0.052 & 0.043 & 0.205 & 0.053 & 0.039 & 0.172 \\
\hline 3. Cash/TA at leverage peak w/o external financing & -0.318 & -0.385 & 0.108 & -0.289 & -0.436 & 0.129 \\
\hline 4. External financing as a $\%$ of cash at peak & $532 \%$ & $718 \%$ & $47 \%$ & $532 \%$ & $844 \%$ & $13 \%$ \\
\hline 5. ML or Net debt/TA at its trough & 0.008 & 0.013 & 0.000 & -0.219 & -0.164 & -0.383 \\
\hline 6. ML or Net debt/TA at its peak & 0.360 & 0.394 & 0.108 & 0.210 & 0.273 & -0.114 \\
\hline 7. Number of years from peak to trough & 6 & 6 & 2 & 6 & 6 & 4 \\
\hline 8. Number of firms & 2,614 & 2,031 & 350 & 2,901 & 2,026 & 575 \\
\hline 9. Percent of sample & $100 \%$ & $85 \%$ & $15 \%$ & $100 \%$ & $78 \%$ & $22 \%$ \\
\hline
\end{tabular}


Table 7

\section{Capital Expenditures and Equity Payouts During Cash-Squeeze and Levering-up Episodes}

The table analyzes the cash-balance squeeze episodes considered in Table 5 and levering up episodes considered in Table 6 . In all cases, total assets are measured as of the end of the episode in question. Capital expenditures and equity payouts (over each cash-squeeze or levering-up episode) are defined in the Appendix.

\begin{tabular}{|c|c|c|c|c|}
\hline \multirow[b]{2}{*}{ Value for median firm of } & \multicolumn{2}{|c|}{$\begin{array}{c}\text { Full sample } \\
\text { Would have run out of cash? }\end{array}$} & \multicolumn{2}{|c|}{$\begin{array}{c}20 \text {-year plus sample } \\
\text { Would have run out of cash? }\end{array}$} \\
\hline & yes & no & yes & no \\
\hline \multicolumn{5}{|l|}{ 1. Capital expenditures as a $\%$ of total assets } \\
\hline Cash-balance squeeze episodes & $20 \%$ & $8 \%$ & $29 \%$ & $15 \%$ \\
\hline Cash squeezes: all-equity external funding & $16 \%$ & $9 \%$ & $34 \%$ & $16 \%$ \\
\hline Levering up: Market leverage & $20 \%$ & $7 \%$ & $26 \%$ & $10 \%$ \\
\hline Levering up: Book leverage & $18 \%$ & $6 \%$ & $24 \%$ & $7 \%$ \\
\hline Levering up: Net-debt ratio & $21 \%$ & $8 \%$ & $28 \%$ & $14 \%$ \\
\hline \multicolumn{5}{|l|}{ 2. Payouts as a $\%$ of total assets } \\
\hline Cash-balance squeeze episodes & $0 \%$ & $0 \%$ & $6 \%$ & $10 \%$ \\
\hline Cash squeezes: all-equity external funding & $0 \%$ & $0 \%$ & $6 \%$ & $6 \%$ \\
\hline Levering up: Market leverage & $<1 \%$ & $0 \%$ & $6 \%$ & $5 \%$ \\
\hline Levering up: Book leverage & $<1 \%$ & $0 \%$ & $6 \%$ & $4 \%$ \\
\hline Levering up: Net-debt ratio & $<1 \%$ & $0 \%$ & $6 \%$ & $12 \%$ \\
\hline \multicolumn{5}{|l|}{ 3. Payouts as a $\%$ of [Payouts + Capital expenditures] } \\
\hline Cash-balance squeeze episodes & $0 \%$ & $1 \%$ & $17 \%$ & $37 \%$ \\
\hline Cash squeezes: all-equity external funding & $0 \%$ & $0 \%$ & $16 \%$ & $34 \%$ \\
\hline Levering up: Market leverage & $1 \%$ & $0 \%$ & $20 \%$ & $31 \%$ \\
\hline Levering up: Book leverage & $1 \%$ & $0 \%$ & $21 \%$ & $33 \%$ \\
\hline Levering up: Net-debt ratio & $<1 \%$ & $0 \%$ & $20 \%$ & $44 \%$ \\
\hline
\end{tabular}




\section{Actual Versus Model-Generated Leverage Changes During Cash Squeezes}

The actual data in the first column are based on the cash squeezes analyzed in Table 5. The remaining columns report model-generated leverage behavior for model samples constructed to mirror the actual sample. Those eight columns consider four scenarios, with DDW referring to the model of DeAngelo, DeAngelo, and Whited (2011) and GT referring to the model of Gamba and Triantis (2008). Both models are designed with a debt-issuance cost and a liquidity cost of cash balances. In the first pair of columns of model-generated results, we consider the model with baseline values of the parameters, as described in the appendix. In the next three pairs of columns, we report results for sensitivity checks that consider (i) a markedly higher value of the liquidity cost parameter (1.1\% instead of $0.35 \%$ ), (ii) a modification of the baseline that allows negative operating profit (up to - $15 \%$ of steady-state capital, excluding cash balances), and (iii) a modification that requires payouts to shareholders of at least $2 \%$ of book equity. See the appendix for details on these sensitivity checks. ML and BL refer to market and book leverage ratios. For both panels, "Yes" in rows 1 or 2 indicates that the median ML or BL - actual or model-generated - increased over the cash-squeeze episode. Rows 3 to 7 consider the data partitioned by whether firms would have run out of cash without external funding during their cash-squeeze episodes. "Yes" in rows 3 or 4 indicates that the median ML or BL change was larger among firms that would have run out of cash than among firms that would not have run out of cash. In columns in which row 1 (row 2) reports a "No," a "Yes" in row 3 (row 4) includes cases in which the ML (BL) change is less negative. Rows 5 and 6 report the differences in median ML and BL for (i) firms that would have run out of cash during the squeeze minus (ii) those that would not have run out of cash during the squeeze.

\begin{tabular}{|c|c|c|c|c|c|c|c|c|c|}
\hline & \multirow{2}{*}{$\begin{array}{l}\text { Actual } \\
\text { data }\end{array}$} & \multicolumn{2}{|c|}{$\begin{array}{c}\text { Baseline } \\
\text { parameter values }\end{array}$} & \multicolumn{2}{|c|}{$\begin{array}{l}\text { High liquidity } \\
\text { cost scenario }\end{array}$} & \multicolumn{2}{|c|}{$\begin{array}{l}\text { Negative operating } \\
\text { profit allowed }\end{array}$} & \multicolumn{2}{|c|}{$\begin{array}{c}\text { Lower bound on } \\
\text { equity payouts }\end{array}$} \\
\hline & & DDW & GT & DDW & GT & DDW & GT & DDW & GT \\
\hline \multicolumn{10}{|l|}{ A. Full sample } \\
\hline 1. ML increase when squeezed for cash? & Yes & Yes & Yes & Yes & Yes & Yes & Yes & Yes & Yes \\
\hline 2. BL increase when squeezed for cash? & Yes & Yes & Yes & Yes & Yes & Yes & Yes & Yes & Yes \\
\hline 3. Larger ML change when running out of cash? & Yes & Yes & Yes & Yes & Yes & Yes & Yes & Yes & Yes \\
\hline 4. Larger BL change when running out of cash? & Yes & Yes & Yes & Yes & Yes & Yes & Yes & Yes & Yes \\
\hline 5. Differential ML change & 0.203 & 0.044 & 0.021 & 0.034 & 0.052 & 0.033 & 0.042 & 0.040 & 0.033 \\
\hline 6. Differential BL change & 0.181 & 0.107 & 0.058 & 0.106 & 0.090 & 0.064 & 0.074 & 0.122 & 0.097 \\
\hline 7. Percent of cases that run out of cash & $64 \%$ & $64 \%$ & $88 \%$ & $92 \%$ & $92 \%$ & $68 \%$ & $87 \%$ & $67 \%$ & $88 \%$ \\
\hline \multicolumn{10}{|l|}{ B. 20-year-plus sample } \\
\hline 1. ML increase when squeezed for cash? & Yes & Yes & Yes & Yes & No & Yes & Yes & Yes & Yes \\
\hline 2. BL increase when squeezed for cash? & Yes & Yes & Yes & Yes & Yes & Yes & Yes & Yes & Yes \\
\hline 3. Larger ML change when running out of cash? & Yes & Yes & Yes & Yes & Yes & Yes & Yes & Yes & Yes \\
\hline 4. Larger BL change when running out of cash? & Yes & Yes & Yes & Yes & Yes & Yes & Yes & Yes & Yes \\
\hline 5. Differential ML change & 0.168 & 0.049 & 0.021 & 0.045 & 0.031 & 0.049 & 0.047 & 0.052 & 0.030 \\
\hline 6. Differential BL change & 0.174 & 0.157 & 0.070 & 0.162 & 0.058 & 0.111 & 0.098 & 0.167 & 0.091 \\
\hline 7. Percent of cases that run out of cash & $68 \%$ & $87 \%$ & $96 \%$ & $97 \%$ & $98 \%$ & $88 \%$ & $96 \%$ & $89 \%$ & $97 \%$ \\
\hline
\end{tabular}




\section{Table 9}

\section{Depth of Cash Squeezes When Firms Lever Up}

This table gauges the scale of the cash-balance depletion that accompanies episodes in which firms lever up to peaks measured in terms of market leverage (ML), book leverage (BL), or the Net debt/TA ratio. The actual data in the first column are based on trough-to-peak levering up episodes, e.g., as analyzed in Table 6. The remaining columns report model-generated cash-squeeze behavior for model samples constructed to mirror the actual sample. Those eight columns consider four scenarios, with DDW referring to the model of DeAngelo, DeAngelo, and Whited (2011) and GT referring to the model of Gamba and Triantis (2008). For details on those scenarios, see the header to Table 8. In the odd numbered rows, the As if Cash/TA ratios are the values (for the median firm) of the cash-balance ratio that would have prevailed absent external funding over the period from leverage trough to peak. The figures in the odd-numbered rows are based on the subset of firms that would have run out of cash without external funding. The even-numbered rows report the percent of the (actual or model-generated) sample firms that would have run out of cash during the levering-up episode had they not raised outside funds.

\begin{tabular}{|c|c|c|c|c|c|c|c|c|c|}
\hline & \multirow{2}{*}{$\begin{array}{c}\text { Actual } \\
\text { data }\end{array}$} & \multicolumn{2}{|c|}{$\begin{array}{c}\text { Baseline } \\
\text { parameter values }\end{array}$} & \multicolumn{2}{|c|}{$\begin{array}{l}\text { High liquidity } \\
\text { cost scenario }\end{array}$} & \multicolumn{2}{|c|}{$\begin{array}{l}\text { Negative operating } \\
\text { profit allowed }\end{array}$} & \multicolumn{2}{|c|}{$\begin{array}{c}\text { Lower bound on } \\
\text { equity payouts }\end{array}$} \\
\hline & & DDW & GT & DDW & GT & DDW & GT & DDW & GT \\
\hline \multicolumn{10}{|l|}{ C. Full sample } \\
\hline 1. As if Cash/TA at ML peak & -0.451 & -0.186 & -0.642 & -0.261 & -0.837 & -0.372 & -0.796 & -0.200 & -0.612 \\
\hline 2. Percent of firms that would have run out of cash & $78 \%$ & $71 \%$ & $63 \%$ & $95 \%$ & $82 \%$ & $61 \%$ & $66 \%$ & $70 \%$ & $64 \%$ \\
\hline 3. As if Cash/TA at BL peak & -0.484 & -0.191 & -0.708 & -0.251 & -0.854 & -0.369 & -0.863 & -0.205 & -0.646 \\
\hline 4. Percent of firms that would have run out of cash & $79 \%$ & $64 \%$ & $70 \%$ & $95 \%$ & $85 \%$ & $41 \%$ & $73 \%$ & $62 \%$ & $69 \%$ \\
\hline 5. As if Cash/TA at peak Net debt/TA & -0.505 & -0.203 & -0.789 & -0.251 & -0.883 & -0.328 & -0.922 & -0.213 & -0.706 \\
\hline 6. Percent of firms that would have run out of cash & $72 \%$ & $68 \%$ & $83 \%$ & $96 \%$ & $90 \%$ & $61 \%$ & $85 \%$ & $70 \%$ & $80 \%$ \\
\hline \multicolumn{10}{|l|}{ D. 20-year-plus sample } \\
\hline 1. As if Cash/TA at ML peak & -0.385 & -0.297 & -1.158 & -0.503 & -2.353 & -0.552 & -1.689 & -0.322 & -1.030 \\
\hline 2. Percent of firms that would have run out of cash & $85 \%$ & $89 \%$ & $79 \%$ & $97 \%$ & $94 \%$ & $79 \%$ & $85 \%$ & $85 \%$ & $82 \%$ \\
\hline 3. As if Cash/TA at BL peak & -0.447 & -0.326 & -1.395 & -0.504 & -2.578 & -0.543 & -2.017 & -0.331 & -1.159 \\
\hline 4. Percent of firms that would have run out of cash & $86 \%$ & $80 \%$ & $87 \%$ & $97 \%$ & $95 \%$ & $52 \%$ & $90 \%$ & $76 \%$ & $86 \%$ \\
\hline 5. As if Cash/TA at peak Net debt/TA & -0.436 & -0.332 & -2.006 & -0.522 & -3.024 & -0.558 & -2.700 & -0.352 & -1.517 \\
\hline 6. Percent of firms that would have run out of cash & $78 \%$ & $87 \%$ & $95 \%$ & $97 \%$ & $97 \%$ & $81 \%$ & $96 \%$ & $87 \%$ & $93 \%$ \\
\hline
\end{tabular}




\section{Table IA1}

\section{Cross-Firm Differences in the Combination of Leverage and Cash-Balance Volatilities}

The sample contains 3,099 nonfinancial firms with at least 20 consecutive years of non-missing values of total book assets, the market value of common stock, and holdings of cash and marketable securities. The columns sort firms into 10 subsamples based on deciles of the time-series median level of the leverage or cashbalance ratio in question. All statistics within a given panel (A, B, C, and D) refer to values for the same sample sorting. For example, in Panel A, rows 1 through 8 all report findings for the sample of 3,099 firms sorted into 10 groups based on each firm's time-series median value of its market-leverage ratio. So, for rows 1 through 8 , the first column contains statistics for the $10 \%$ of sample firms that have the lowest time-series median market leverage, while the tenth column contains statistics for the $10 \%$ of sample firms with the highest time-series median of market leverage. The numbers in the body of the table equal the cross-firm medians (among firms that are in the decile-based grouping) of the statistic in question. Market leverage (ML) equals the book value of debt divided by sum of the book value of debt and the market value of common stock. Book leverage (BL) equals the book value of debt divided by the book value of total assets. The cash-balance ratio (Cash/TA) equals total cash plus marketable securities divided by total assets. The net-debt ratio (Net debt/TA) equals BL minus Cash/TA. The symbol $\sigma$ denotes standard deviation.

\begin{tabular}{|c|c|c|c|c|c|c|c|c|c|c|c|}
\hline $\begin{array}{l}\text { Value for the median firm in the } \\
\text { specified sample sorting: }\end{array}$ & $\begin{array}{r}\text { San } \\
\text { Lowest } \\
\text { group }\end{array}$ & $\begin{array}{c}\text { le sortec } \\
\text { Group } \\
2 \\
\end{array}$ & $\begin{array}{l}\text { y each fi } \\
\text { Group } \\
3 \\
\end{array}$ & $\begin{array}{l}\text { 's time- } \\
\text { Group } \\
4\end{array}$ & $\begin{array}{c}\text { ries med } \\
\text { Group } \\
5 \\
\end{array}$ & $\begin{array}{c}\text { n level o } \\
\text { Group } \\
6\end{array}$ & $\begin{array}{c}\text { ML, BL, } \\
\text { Group } \\
7 \\
\end{array}$ & $\begin{array}{c}\text { ash/TA, } \\
\text { Group } \\
8 \\
\end{array}$ & $\begin{array}{l}\text { Net deb } \\
\text { Group } \\
9\end{array}$ & $\begin{array}{l}\text { TA: } \\
\text { Highest } \\
\text { group }\end{array}$ & $\begin{array}{c}\text { Ratio of } \\
\text { Highest to } \\
\text { Lowest }\end{array}$ \\
\hline \multicolumn{12}{|l|}{ A. Market leverage (ML) sorting } \\
\hline 1. $\sigma(\mathrm{ML})$ & 0.046 & 0.080 & 0.094 & 0.110 & 0.136 & 0.150 & 0.157 & 0.176 & 0.183 & 0.187 & 4.1 \\
\hline 2. $\sigma(\mathrm{BL})$ & 0.058 & 0.102 & 0.101 & 0.107 & 0.109 & 0.110 & 0.103 & 0.113 & 0.112 & 0.118 & 2.0 \\
\hline 3. $\sigma(\mathrm{Cash} / \mathrm{TA})$ & 0.141 & 0.123 & 0.102 & 0.083 & 0.074 & 0.064 & 0.050 & 0.052 & 0.046 & 0.049 & 0.3 \\
\hline 4. $\sigma($ Net debt/TA $)$ & 0.178 & 0.193 & 0.168 & 0.167 & 0.151 & 0.154 & 0.129 & 0.142 & 0.135 & 0.140 & 0.8 \\
\hline 5. Time-series median ML & 0.000 & 0.017 & 0.059 & 0.107 & 0.156 & 0.208 & 0.263 & 0.334 & 0.424 & 0.579 & --- \\
\hline 6. Time-series median BL & 0.000 & 0.029 & 0.094 & 0.145 & 0.192 & 0.214 & 0.249 & 0.283 & 0.326 & 0.419 & --- \\
\hline 7. Time-series median Cash/TA & 0.323 & 0.201 & 0.133 & 0.096 & 0.068 & 0.058 & 0.050 & 0.043 & 0.041 & 0.048 & --- \\
\hline 8. Time-series median Net debt/TA & -0.303 & -0.151 & -0.030 & 0.050 & 0.101 & 0.147 & 0.190 & 0.228 & 0.281 & 0.364 & --- \\
\hline \multicolumn{12}{|l|}{ B. Book leverage (BL) sorting } \\
\hline 9. $\sigma(\mathrm{ML})$ & 0.049 & 0.087 & 0.114 & 0.128 & 0.142 & 0.147 & 0.144 & 0.163 & 0.176 & 0.186 & 3.8 \\
\hline 10. $\sigma(\mathrm{BL})$ & 0.057 & 0.092 & 0.100 & 0.102 & 0.105 & 0.106 & 0.108 & 0.110 & 0.124 & 0.142 & 2.5 \\
\hline 11. $\sigma(\mathrm{Cash} / \mathrm{TA})$ & 0.141 & 0.114 & 0.100 & 0.085 & 0.067 & 0.062 & 0.053 & 0.048 & 0.047 & 0.052 & 0.4 \\
\hline 12. $\sigma($ Net debt/TA $)$ & 0.174 & 0.178 & 0.171 & 0.158 & 0.145 & 0.143 & 0.135 & 0.130 & 0.148 & 0.164 & 0.9 \\
\hline 13. Time-series median ML & 0.000 & 0.017 & 0.068 & 0.120 & 0.185 & 0.217 & 0.258 & 0.324 & 0.410 & 0.524 & --- \\
\hline 14. Time-series median BL & 0.000 & 0.027 & 0.086 & 0.135 & 0.179 & 0.218 & 0.254 & 0.296 & 0.354 & 0.470 & --- \\
\hline 15. Time-series median Cash/TA & 0.312 & 0.190 & 0.121 & 0.092 & 0.071 & 0.058 & 0.048 & 0.042 & 0.041 & 0.046 & --- \\
\hline 16. Time-series median Net debt/TA & -0.297 & -0.145 & -0.032 & 0.043 & 0.099 & 0.155 & 0.202 & 0.246 & 0.307 & 0.415 & --- \\
\hline
\end{tabular}

(table continued) 


\begin{tabular}{|c|c|c|c|c|c|c|c|c|c|c|c|}
\hline $\begin{array}{l}\text { Value for the median firm in the } \\
\text { specified sample sorting: }\end{array}$ & $\begin{array}{l}\text { Sar } \\
\text { Lowest } \\
\text { group }\end{array}$ & $\begin{array}{l}\text { le sortec } \\
\text { Group } \\
2 \\
\end{array}$ & $\begin{array}{l}\text { y each fi } \\
\text { Group } \\
3\end{array}$ & $\begin{array}{l}\text { n's time- } \\
\text { Group } \\
4\end{array}$ & $\begin{array}{l}\text { ries med } \\
\text { Group } \\
5\end{array}$ & $\begin{array}{c}\text { n level } \\
\text { Group } \\
6\end{array}$ & $\begin{array}{c}\text { ML, BL } \\
\text { Group } \\
7 \\
\end{array}$ & $\begin{array}{c}\text { ash/TA, } \\
\text { Group } \\
8\end{array}$ & $\begin{array}{l}\text { Net del } \\
\text { Group } \\
9\end{array}$ & $\begin{array}{l}\text { TA } \\
\text { Highest } \\
\text { group }\end{array}$ & $\begin{array}{c}\text { Ratio of } \\
\text { Highest to } \\
\text { Lowest }\end{array}$ \\
\hline \multicolumn{12}{|l|}{ C. Cash-balance ratio (Cash/TA) sorting } \\
\hline 17. $\sigma(\mathrm{ML})$ & 0.154 & 0.157 & 0.160 & 0.155 & 0.153 & 0.158 & 0.142 & 0.117 & 0.090 & 0.064 & 0.4 \\
\hline 18. $\sigma(\mathrm{BL})$ & 0.109 & 0.105 & 0.110 & 0.107 & 0.107 & 0.112 & 0.102 & 0.105 & 0.096 & 0.094 & 0.9 \\
\hline 19. $\sigma(\mathrm{Cash} / \mathrm{TA})$ & 0.029 & 0.042 & 0.050 & 0.051 & 0.061 & 0.073 & 0.083 & 0.103 & 0.133 & 0.163 & 5.6 \\
\hline 20. $\sigma($ Net debt/TA $)$ & 0.122 & 0.125 & 0.138 & 0.132 & 0.148 & 0.157 & 0.157 & 0.177 & 0.196 & 0.210 & 1.7 \\
\hline 21. Time-series median ML & 0.318 & 0.309 & 0.283 & 0.266 & 0.239 & 0.192 & 0.143 & 0.074 & 0.022 & 0.002 & --- \\
\hline 22. Time-series median BL & 0.306 & 0.273 & 0.261 & 0.245 & 0.227 & 0.205 & 0.159 & 0.112 & 0.039 & 0.005 & --- \\
\hline 23. Time-series median Cash/TA & 0.014 & 0.027 & 0.038 & 0.052 & 0.067 & 0.084 & 0.112 & 0.154 & 0.238 & 0.433 & --- \\
\hline 24. Time-series median Net debt/TA & 0.283 & 0.237 & 0.216 & 0.189 & 0.155 & 0.110 & 0.046 & -0.039 & -0.179 & -0.374 & --- \\
\hline \multicolumn{12}{|l|}{ D. Net-debt ratio (Net debt/TA) sorting } \\
\hline $25 . \sigma(\mathrm{ML})$ & 0.053 & 0.089 & 0.105 & 0.127 & 0.144 & 0.144 & 0.158 & 0.162 & 0.174 & 0.184 & 3.5 \\
\hline 26. $\sigma(\mathrm{BL})$ & 0.074 & 0.096 & 0.097 & 0.100 & 0.103 & 0.106 & 0.111 & 0.108 & 0.119 & 0.130 & 1.8 \\
\hline 27. $\sigma(\mathrm{Cash} / \mathrm{TA})$ & 0.159 & 0.127 & 0.099 & 0.084 & 0.073 & 0.060 & 0.054 & 0.047 & 0.043 & 0.041 & 0.3 \\
\hline 28. $\sigma($ Net debt/TA $)$ & 0.203 & 0.188 & 0.169 & 0.154 & 0.148 & 0.139 & 0.136 & 0.129 & 0.141 & 0.150 & 0.7 \\
\hline 29. Time-series median ML & 0.000 & 0.017 & 0.052 & 0.103 & 0.171 & 0.215 & 0.263 & 0.315 & 0.390 & 0.521 & --- \\
\hline 30. Time-series median BL & 0.001 & 0.023 & 0.078 & 0.123 & 0.170 & 0.208 & 0.243 & 0.284 & 0.341 & 0.461 & --- \\
\hline 31. Time-series median Cash/TA & 0.419 & 0.222 & 0.137 & 0.096 & 0.074 & 0.057 & 0.049 & 0.038 & 0.034 & 0.034 & --- \\
\hline 32. Time-series median Net debt/TA & -0.374 & -0.167 & -0.054 & 0.027 & 0.087 & 0.145 & 0.191 & 0.240 & 0.299 & 0.415 & --- \\
\hline
\end{tabular}




\section{Table IA2}

\section{Cross-Firm Differences in the Combination of Leverage and Cash-Balance Volatilities}

The sample contains 3,099 nonfinancial firms with at least 20 consecutive years of non-missing values of total book assets, the market value of common stock, and holdings of cash and marketable securities. The columns sort firms into 10 subsamples based on deciles of the time-series standard deviation ( $\sigma$ ) of the leverage or cash-balance ratio in question. All statistics within a given panel (A, B, C, and D) refer to values for the same sample sorting. For example, in Panel A, rows 1 through 8 all report findings for the sample of 3,099 firms sorted into 10 groups based on each firm's $\sigma(\mathrm{ML})$. So, for rows 1 through 8 , the first column contains statistics for the $10 \%$ of sample firms that have the lowest $\sigma(\mathrm{ML})$, while the tenth column contains statistics for the $10 \%$ of sample firms with the highest $\sigma(\mathrm{ML})$. The numbers in the body of the table equal the cross-firm medians (among firms that are in the decile-based grouping) of the statistic in question. Market leverage (ML) equals the book value of debt divided by sum of the book value of debt and the market value of common stock. Book leverage (BL) equals the book value of debt divided by the book value of total assets. The cash-balance ratio (Cash/TA) equals total cash plus marketable securities divided by total assets. The netdebt ratio (Net debt/TA) equals BL minus Cash/TA.

\begin{tabular}{|c|c|c|c|c|c|c|c|c|c|c|c|}
\hline $\begin{array}{l}\text { Value for the median firm in the } \\
\text { specified sample sorting: }\end{array}$ & $\begin{array}{l}\text { Sa } \\
\text { Lowest } \\
\text { group }\end{array}$ & $\begin{array}{c}\text { ple sorte } \\
\text { Group } \\
2 \\
\end{array}$ & $\begin{array}{c}\text { by each } f \\
\text { Group } \\
3 \\
\end{array}$ & $\begin{array}{c}\text { m's stan } \\
\text { Group } \\
4 \\
\end{array}$ & $\begin{array}{l}\text { rd devia } \\
\text { Group } \\
5\end{array}$ & $\begin{array}{l}\text { of }(\sigma) \text { of } \\
\text { Group } \\
6\end{array}$ & $\begin{array}{c}\mathrm{L}, \mathrm{BL}, \\
\text { Group } \\
7 \\
\end{array}$ & $\begin{array}{c}\text { sh/TA, o } \\
\text { Group } \\
8\end{array}$ & $\begin{array}{c}\text { Net debt } \\
\text { Group } \\
9 \\
\end{array}$ & $\begin{array}{l}\text { A: } \\
\text { Highest } \\
\text { group }\end{array}$ & $\begin{array}{c}\text { Ratio of } \\
\text { Highest to } \\
\text { Lowest }\end{array}$ \\
\hline \multicolumn{12}{|l|}{ A. Market leverage (ML) sorting } \\
\hline 1. $\sigma(\mathrm{ML})$ & 0.031 & 0.068 & 0.089 & 0.109 & 0.128 & 0.146 & 0.166 & 0.189 & 0.215 & 0.257 & 8.3 \\
\hline 2. $\sigma(\mathrm{BL})$ & 0.046 & 0.079 & 0.084 & 0.087 & 0.098 & 0.104 & 0.115 & 0.130 & 0.145 & 0.184 & 4.0 \\
\hline 3. $\sigma(\mathrm{Cash} / \mathrm{TA})$ & 0.116 & 0.086 & 0.075 & 0.061 & 0.066 & 0.065 & 0.062 & 0.064 & 0.072 & 0.075 & 0.6 \\
\hline 4. $\sigma($ Net debt/TA $)$ & 0.142 & 0.136 & 0.137 & 0.123 & 0.138 & 0.138 & 0.150 & 0.167 & 0.187 & 0.225 & 1.6 \\
\hline 5. Time-series median ML & 0.001 & 0.063 & 0.107 & 0.163 & 0.179 & 0.221 & 0.252 & 0.310 & 0.297 & 0.340 & --- \\
\hline 6. Time-series median BL & 0.002 & 0.110 & 0.158 & 0.191 & 0.204 & 0.217 & 0.236 & 0.265 & 0.262 & 0.281 & --- \\
\hline 7. Time-series median Cash/TA & 0.279 & 0.136 & 0.085 & 0.071 & 0.068 & 0.057 & 0.059 & 0.052 & 0.064 & 0.062 & --- \\
\hline 8. Time-series median Net debt/TA & -0.256 & -0.033 & 0.053 & 0.107 & 0.121 & 0.151 & 0.186 & 0.209 & 0.188 & 0.223 & --- \\
\hline \multicolumn{12}{|l|}{ B. Book leverage (BL) sorting } \\
\hline 9. $\sigma(\mathrm{ML})$ & 0.046 & 0.099 & 0.106 & 0.119 & 0.135 & 0.147 & 0.164 & 0.185 & 0.197 & 0.214 & 4.7 \\
\hline 10. $\sigma(\mathrm{BL})$ & 0.038 & 0.060 & 0.074 & 0.086 & 0.099 & 0.112 & 0.126 & 0.145 & 0.173 & 0.232 & 6.1 \\
\hline 11. $\sigma(\mathrm{Cash} / \mathrm{TA})$ & 0.089 & 0.058 & 0.057 & 0.063 & 0.064 & 0.070 & 0.074 & 0.083 & 0.090 & 0.111 & 1.2 \\
\hline 12. $\sigma($ Net debt/TA $)$ & 0.102 & 0.092 & 0.104 & 0.123 & 0.133 & 0.149 & 0.168 & 0.193 & 0.222 & 0.299 & 2.9 \\
\hline 13. Time-series median ML & 0.010 & 0.182 & 0.186 & 0.172 & 0.196 & 0.210 & 0.204 & 0.201 & 0.220 & 0.185 & --- \\
\hline 14. Time-series median BL & 0.013 & 0.163 & 0.199 & 0.191 & 0.194 & 0.217 & 0.222 & 0.217 & 0.241 & 0.257 & --- \\
\hline 15. Time-series median Cash/TA & 0.189 & 0.073 & 0.068 & 0.063 & 0.067 & 0.063 & 0.068 & 0.063 & 0.080 & 0.091 & --- \\
\hline 16. Time-series median Net debt/TA & -0.159 & 0.073 & 0.130 & 0.122 & 0.121 & 0.150 & 0.141 & 0.153 & 0.164 & 0.147 & --- \\
\hline
\end{tabular}

(table continued) 


\begin{tabular}{|c|c|c|c|c|c|c|c|c|c|c|c|}
\hline $\begin{array}{l}\text { Value for the median firm in the } \\
\text { specified sample sorting: }\end{array}$ & $\begin{array}{r}\mathrm{Sa} \\
\text { Lowest } \\
\text { group }\end{array}$ & $\begin{array}{c}\text { ple sorte } \\
\text { Group } \\
2 \\
\end{array}$ & $\begin{array}{c}\text { by each } \\
\text { Group } \\
3\end{array}$ & $\begin{array}{c}\text { m's stan } \\
\text { Group } \\
4 \\
\end{array}$ & $\begin{array}{l}\text { rd deviat } \\
\text { Group } \\
5\end{array}$ & $\begin{array}{l}\text { of }(\sigma) \text { of } \\
\text { Group } \\
6\end{array}$ & $\begin{array}{c}\text { IL, BL, } \\
\text { Group } \\
7 \\
\end{array}$ & $\begin{array}{c}\text { sh/TA, } \\
\text { Group } \\
8\end{array}$ & $\begin{array}{c}\text { Net debt } \\
\text { Group } \\
9\end{array}$ & $\begin{array}{l}\text { A: } \\
\text { Highest } \\
\text { group }\end{array}$ & $\begin{array}{c}\text { Ratio of } \\
\text { Highest to } \\
\text { Lowest }\end{array}$ \\
\hline \multicolumn{12}{|c|}{ C. Cash-balance ratio (Cash/TA) sorting } \\
\hline 17. $\sigma(\mathrm{ML})$ & 0.142 & 0.143 & 0.139 & 0.155 & 0.151 & 0.147 & 0.137 & 0.123 & 0.115 & 0.108 & 0.8 \\
\hline 18. $\sigma(\mathrm{BL})$ & 0.090 & 0.094 & 0.093 & 0.101 & 0.105 & 0.110 & 0.111 & 0.105 & 0.123 & 0.133 & 1.5 \\
\hline 19. $\sigma(\mathrm{Cash} / \mathrm{TA})$ & 0.020 & 0.034 & 0.045 & 0.056 & 0.067 & 0.080 & 0.098 & 0.118 & 0.150 & 0.205 & 10.3 \\
\hline 20. $\sigma($ Net debt/TA $)$ & 0.094 & 0.108 & 0.117 & 0.131 & 0.143 & 0.157 & 0.171 & 0.187 & 0.222 & 0.287 & 3.1 \\
\hline 21. Time-series median ML & 0.352 & 0.317 & 0.249 & 0.262 & 0.208 & 0.163 & 0.121 & 0.074 & 0.049 & 0.024 & --- \\
\hline 22. Time-series median BL & 0.301 & 0.289 & 0.241 & 0.232 & 0.211 & 0.185 & 0.150 & 0.107 & 0.078 & 0.046 & --- \\
\hline 23. Time-series median Cash/TA & 0.023 & 0.038 & 0.049 & 0.060 & 0.070 & 0.084 & 0.114 & 0.163 & 0.207 & 0.282 & --- \\
\hline 24. Time-series median Net debt/TA & 0.266 & 0.244 & 0.185 & 0.169 & 0.142 & 0.087 & 0.032 & -0.050 & -0.109 & -0.204 & --- \\
\hline \multicolumn{12}{|l|}{ D. Net-debt ratio (Net debt/TA) sorting } \\
\hline $25 . \sigma(\mathrm{ML})$ & 0.100 & 0.115 & 0.126 & 0.135 & 0.139 & 0.151 & 0.151 & 0.176 & 0.167 & 0.183 & 1.8 \\
\hline 26. $\sigma(\mathrm{BL})$ & 0.056 & 0.074 & 0.086 & 0.098 & 0.106 & 0.115 & 0.127 & 0.140 & 0.164 & 0.214 & 3.8 \\
\hline 27. $\sigma(\mathrm{Cash} / \mathrm{TA})$ & 0.035 & 0.045 & 0.052 & 0.060 & 0.070 & 0.080 & 0.091 & 0.107 & 0.134 & 0.175 & 5.0 \\
\hline 28. $\sigma($ Net debt/TA $)$ & 0.069 & 0.093 & 0.112 & 0.128 & 0.146 & 0.164 & 0.186 & 0.213 & 0.252 & 0.319 & 4.6 \\
\hline 29. Time-series median ML & 0.275 & 0.243 & 0.220 & 0.187 & 0.182 & 0.168 & 0.162 & 0.149 & 0.124 & 0.084 & --- \\
\hline 30. Time-series median BL & 0.256 & 0.226 & 0.213 & 0.202 & 0.196 & 0.181 & 0.184 & 0.169 & 0.155 & 0.139 & --- \\
\hline 31. Time-series median Cash/TA & 0.050 & 0.051 & 0.055 & 0.065 & 0.071 & 0.085 & 0.086 & 0.100 & 0.104 & 0.174 & --- \\
\hline 32. Time-series median Net debt/TA & 0.208 & 0.167 & 0.157 & 0.137 & 0.117 & 0.099 & 0.094 & 0.070 & 0.047 & -0.039 & --- \\
\hline
\end{tabular}




\section{Data Appendix}

\section{Main variables}

Throughout the paper, we focus on four main ratios:

- cash-balance ratio: $\mathrm{Cash} / \mathrm{TA}=\mathrm{Cash} /$ Total Assets

- $\quad$ market-leverage ratio: $\mathrm{ML}=\mathrm{Debt} /($ Debt+Market Equity)

- book-leverage ratio: $\mathrm{BL}=\mathrm{Debt} /$ Total Assets

- net-debt ratio: (Debt-Cash)/Total Assets

Here are the data sources and components of these ratios, with standard mnemonic definitions for COMPUSTAT and CRSP given in parentheses. Total Assets (AT), Cash (CHE), and Debt (DLTT+DLC) are from COMPUSTAT and Market Equity is from CRSP (SHROUT*PRC) if available and otherwise from COMPUSTAT (PRCC_F*CSHO). CRSP variables are restricted to common shares (SHRCD $=10$ or 11) and linked to COMPUSTAT by PERMNO and the calendar date of the COMPUSTAT fiscal year end. For each firm, Market Equity is the sum of the market equity amounts of all PERMNOs linked to that firm's GVKEY.

In calculating these ratios, we set any missing DLTT and DLC to zero as long as at least one of these two variables is available. We also set to missing any $\mathrm{AT} \leq 0$, Debt $<0, \mathrm{CHE}<0$, and $\mathrm{PRC} \leq 0$.

\section{Hypothetical cash holdings if the firm had not raised external funds}

In our analysis of cash-balance squeezes, we calculate the hypothetical amount of cash a firm would have at the end of an event period if it had not raised outside funds. Here, we use the symbol NoExtCap Cash to represent that hypothetical cash amount. The event is either a period in which Cash/TA is decreasing or Leverage is increasing. However, the definition of NoExtCap Cash is the same for both types of events.

Here and below,let $\mathrm{t}$ denote the year right before the event starts and $\mathrm{T}$ denote the final year of the event window so that:

where

$$
\text { NoExtCap Cash }(\mathrm{T})=\mathrm{CHE}(\mathrm{T})-\text { Debt Proceeds }(\mathrm{t} \text { to } \mathrm{T})-\text { Equity Proceeds }(\mathrm{t} \text { to } \mathrm{T})
$$

$$
\begin{aligned}
& \text { Debt Proceeds }(\mathrm{t} \text { to T })=\operatorname{MAX}\{\operatorname{Debt}(\mathrm{T})-\operatorname{Debt}(\mathrm{t}), 0\} \\
& \text { Equity Proceeds }(\mathrm{t} \text { to } \mathrm{T})=\sum_{\mathrm{h}=\mathrm{t}}^{\mathrm{T}} \text { Equity Proceeds }(\mathrm{h}) * \mathrm{CPI}(\mathrm{T}) / \mathrm{CPI}(\mathrm{h}) \\
& \text { Equity Proceeds }(\mathrm{h})=\operatorname{MAX}\{\text { Equity Issuances(h) }- \text { Equity Repurchases }(\mathrm{h}), 0\} \\
& \text { Equity Issuances }(\mathrm{h})=\operatorname{MAX}\{\operatorname{SSTK}(\mathrm{h})-\operatorname{MAX}[\operatorname{BVPS}(\mathrm{h})-\operatorname{BVPS}(\mathrm{h}-1), 0], 0\} \\
& \text { Equity Repurchases(h) }=\operatorname{MAX}\{\operatorname{PRSTKC}+\operatorname{MIN}[\operatorname{BVPS}(\mathrm{h})-\operatorname{BVPS}(\mathrm{h}-1), 0], 0\}
\end{aligned}
$$

CPI reflects the consumer price index available on the webpage of the Federal Reserve of St. Louis. The reason we include CPI adjustments in these variable definitions is to take account of differences in the timing of arrival of proceeds within a given episode. 
SSTK and PRSTKC are from COMPUSTAT and reflect sales/purchases of common and preferred stock, with BVPS capturing the book value of preferred shares and defined as the COMPUSTAT variable PSTKRV, PSTKL, or PSTK (in this order of availability).

When the data needed to calculate Equity Issuances or Repurchases are missing from COMPUSTAT, we obtain Net Equity Issuances directly from CRSP and use Equity Proceeds(h) = MAX \{ Net Equity Issuances(h), 0 \} instead of the above definition. Specifically, we obtain monthly Net Equity Issuances as the average PRC multiplied by the change in SHROUT (everything split adjusted) and then sum the monthly Net Equity Issuances over the months associated with the relevant firm's fiscal year.

In Tables 5 to 7 and Figures 5 and 6, we use the hypothetical level of cash balances (NoExtCap Cash) in two distinct ways. First, we partition our sample into firms that would run out of cash in the absence of external financing (NoExtCap Cash $\leq 0$ ) and firms that would not (NoExtCap Cash $>0$ ). Second, we calculate hypothetical cash-balance ratios, which we define as follows:

where

$$
\text { NoExtCap Cash/TA = NoExtCap Cash / NoExtCap AT }
$$

$$
\text { NoExtCap AT }=\operatorname{MAX}\{\text { AT(T) }- \text { Debt Proceeds }(t \text { to } T)-\text { Equity Proceeds }(t \text { to } T), 0\}
$$

\section{Other variable definitions}

Tables 5 and 6 (and Figures 5 and 6) report two other variables that capture the extent of external financing over a firm's cash-squeeze or levering up episode:

External financing as a fraction of cash held at the end of the episode $=$ External Financing $/$ Cash at Peak or Trough $=\{$ Debt Proceeds $(\mathrm{t}$ to $\mathrm{T})+$ Equity Proceeds(t to T) $\} / \mathrm{CHE}(\mathrm{T})$.

Proportion of external financing during the episode that comes from debt $=\delta=$ Debt Proceeds $(\mathrm{t}$ to T) $/ \operatorname{MAX}\{$ Debt Proceeds(t to T) + Net Equity Proceeds(t to T), 0$\}$ where Net Equity Proceeds $(\mathrm{t}$ to $\mathrm{T})=\sum_{\mathrm{h}=\mathrm{t}}^{\mathrm{T}}\{$ Equity Issuances(h) - Equity Repurchases(h) $\} * \mathrm{CPI}(\mathrm{T}) / \mathrm{CPI}(\mathrm{h})$.

Table 7 uses two other variables related to payout and investment:

Payouts over a firm's cash-squeeze episode $=$ Payouts $(\mathrm{t}$ to $\mathrm{T})=\sum_{\mathrm{h}=\mathrm{t}}^{\mathrm{T}}$ \{Dividends + MAX[Equity Repurchases(h) - Equity Issuances(h), 0]\} * CPI(T)/CPI(h).

Capital expenditures over a firm's cash-squeeze episode $=$ Capital Expenditures $(\mathrm{t}$ to $\mathrm{T})=$ $\sum_{\mathrm{h}=\mathrm{t}}^{\mathrm{T}}$ Capital Expenditures(h) where Capital Expenditures (CAPEX) and Dividends (MAX $\{$ DVC, 0$\})$ are measured from COMPUSTAT. 


\section{Models}

\section{Model Appendix}

We consider two models that are cash-balance-related extensions of Hennessy and Whited's (2005) dynamic tradeoff model: Gamba and Triantis (2008, GT) and DeAngelo, DeAngelo, and Whited (2011, DDW). We make a few small adjustments to each model to better reflect our focus on the relation between leverage and cash-balance ratios.

In the original GT formulation, firms never pay down their debt because issuing debt is costly whereas there is no cost associated with holding cash or changing cash balances. Consequently, debt repayment is optimally dominated by increasing cash changes. Since this feature of GT is clearly not descriptive of realworld behavior, we add a liquidity (or agency) cost of holding cash as in DDW. This liquidity cost effectively dictates a spread between the interest rate that firms pay on their debt and the interest rate they receive on their cash balances. In this model specification, cash balances are costly to hold because they pay an interest rate that is lower than the interest rate firms pay on their debt. Consequently, firms adjust leverage through both cash and debt changes as each has its own costs and benefits.

In the formulation that DDW highlight in their paper, firms never hold positive amounts of cash and debt simultaneously because there is an agency cost of holding cash and no cost of issuing debt. Consequently, a decision to use cash to pay off debt would leave the tax bill unchanged and reduce agency costs. Since this model prediction is clearly at odds with reality, we add a debt-issuance cost analogous to the one in GT and in the formulation treated in section 7 of DDW. This model specification leads firms to hold cash and debt simultaneously as each has its own costs and benefits. ${ }^{1}$

\section{Calibrations}

We refer the reader to GT and DDW for details related to the models and their original calibrations. Here, we provide information on our calibration, which is summarized in Table A1. Most numbers are set to the ones used in DDW and GT. Below, we provide further information only on the numbers that we change relative to their original calibrations.

In our implementation of GT, only three parameters are calibrated to values that differ from their original calibration. First, as explained above, we add a liquidity (agency) cost of holding cash. We set the liquidity cost parameter to equal the value we use in DDW, $\phi=0.0035$, with details provided in the DDW calibration explanation below. Second, we change (relative to the original calibration) the autocorrelation and standard deviation of the productivity/profitability state variable. In particular, we want this exogenous state variable to have the same dynamics in both GT and DDW so that we know differences across the two models are driven by the parameters related to endogenous decisions. We accordingly use the values in our DDW calibration, which are $\rho=0.7280$ for the autocorrelation and $\sigma=0.3500$ for the standard deviation of shocks (as opposed to the GT original values of $\rho=0.6200$ and $\sigma=0.1500$ ).

In our implementation of DDW, only five parameters are calibrated to values that differ from their original calibration. First, as explained above, we add a linear debt issuance cost. We set the debt adjustment cost parameter to reflect a cost of $2 \%$ of the debt issuance size $(\theta=0.0200)$, which matches the GT calibration. Second, we change the liquidity (agency) cost of holding cash to $\phi=0.0035$ (instead of the $\phi=0.0077$ originally used) to better reflect recent evidence in Binsbergen, Diamond, and Grotteria (2021) that the

\footnotetext{
${ }^{1}$ We also correct two glitches in the model description in DDW. Specifically, the equity issuance adjustment cost function is given by $\mathrm{f}(\mathrm{x})=\lambda_{0} \cdot \mathrm{x}-\lambda_{1} \cdot \mathrm{x}^{2}$ instead of $\mathrm{f}(\mathrm{x})=\lambda_{0} \cdot \mathrm{x}-0.5 \cdot \lambda_{1} \cdot \mathrm{x}^{2}$ and the steady-state capital expression is given by $\mathrm{k}_{\mathrm{ss}}=[\alpha /(\mathrm{r}+\delta)]^{\wedge}[1 /(1-\alpha)]$ instead of $\mathrm{k}_{\mathrm{ss}}=\left[\left(1-\tau_{\mathrm{c}}\right) \cdot \alpha /(\mathrm{r}+\delta)\right]^{\wedge}[1 /(1-\alpha)]$.
} 
average convenience yield on a one-month Treasury bill is between 38 and 65 basis points. ${ }^{2}$ These two adjustments change the model moments so we adjust three other parameters to make sure the model continues to match well the data moments reported in Table 1 of DDW. Specifically, we change the real interest rate from $\mathrm{r}=1.5 \%$ to $\mathrm{r}=2.0 \%$, the debt upper bound (as a fraction of steady-state capital) from $\mathrm{u}=0.7196$ to $\mathrm{u}=0.6000$, and the standard deviation of productivity/profitability shocks from $\sigma=0.2843$ to $\sigma=0.3500$. These three relatively small adjustments enable our version of DDW to closely match the data moments in their Table 1.

\section{Numerical Solutions}

To find a numerical solution for each model on a grid, we need to specify a finite state space for the four state variables in each model.

For both models, we let the exogenous productivity/profitability state variable take nine possible values obtained as a discretization of the respective autoregressive processes into discrete-state Markov chains on the interval $[-3 \cdot \mathrm{v}, 3 \cdot \mathrm{v}]$. Here, we follow the method in Tauchen (1986), with $\mathrm{v}^{2}=\sigma^{2} /(1-\rho)$ representing the unconditional variance of the state variable.

In the GT formulation, we let the capital stock take 33 possible values in the space of $\left[k_{\mathrm{u}} \cdot(1-\delta)^{\mathrm{n}}\right]$ with $\mathrm{n}$ from -16 to 16 and $\mathrm{k}_{\mathrm{u}}=30$. We let debt and cash take 23 and 7 possible values, respectively. The debt and cash grids are equally spaced and cover the interval from 0 to $0.4 \cdot \mathrm{k}_{\mathrm{u}}$ in the case of debt and from 0 to $(6 / 22) \cdot 0.4 \cdot k_{u}$ in the case of cash, which assures the space between grid points is the same for the cash and debt grids.

In the DDW formulation, we let the capital stock take 33 possible values in the space of $\left[\mathrm{kss}_{\mathrm{ss}} \cdot(1-\delta)^{\mathrm{n}}\right]$ with $\mathrm{n}$ from -16 to 16 and kss representing the model's steady state capital. We let debt and cash take 13 and 17 possible values, respectively. The debt and cash grids are equally spaced and cover the interval from 0 to $\mathrm{u} \cdot \mathrm{k}_{\mathrm{ss}}$ in the case of debt and from 0 to $(16 / 12) \cdot \mathrm{u} \cdot \mathrm{k}_{\mathrm{ss}}$ in the case of cash, which assures the space between grid points is the same for the cash and debt grids.

We solve both models via iteration on the Bellman equation (i.e., using value function iteration), which produces each model's value function as well as their capital, debt, and cash policy functions, with the latter also needed for the simulations.

\section{Simulations}

For the simulations of both models, we apply multilinear interpolation to the value and policy functions and, following DDW, expand the productivity/profitability state-variable space to 152 points. We then perform a simulation of $100+199,821$ periods, drop the first 100 periods of the simulation (to remove the dependence of the simulation on initial conditions), and use the remaining 199,821 periods of simulation to create a panel of 17,245 firms observed from periods ranging from 2 to 68 years (so that the distribution of firm-year observations matches our empirical sample).

\footnotetext{
${ }^{2}$ Since firms tend to invest their cash balances in money-market accounts, which are composed of securities with maturities of at most 60 days, we interpret the one-month Treasury bill convenience yield as a proxy for the difference between the interest rate on the firm's one-period debt relative to the interest rate on the firm's cash balance (both evaluated before corporate taxes). In the model, this quantity is given by $\phi /\left(1-\tau_{\mathrm{c}}\right)$. Hence, the $\phi=0.0035$ and $\tau_{\mathrm{c}}=0.3500$ values translate into a convenience yield of roughly $0.0035 /(1-0.35)=0.0054$, which is in line with the evidence in Binsbergen, Diamond, and Grotteria (2021).
} 
We follow the procedure in the prior paragraph 11 times to obtain multiple panels and perform the same empirical analysis we do with the actual data on each of these panels. Each final number we report reflects the median statistic obtained across these 11 panels. This process is similar to the one in DDW, except that we use medians and 11 instead of 10 panels so that there is no averaging in the median calculation.

\section{Extensions}

We also report results related to three independent extensions of the DDW and GT models.

In the first extension, we simply consider five alternative values for the liquidity (agency) cost parameter associated with cash holdings. Specifically, $\phi$ takes the alternative values of 0.000, 0.0010, 0.0060, 0.0085, and 0.0110 .

In the second extension, we change the unconditional distribution of the gross profit function to create a non-trivial likelihood of negative gross profits. We explain the details below.

Note first that the gross profit function in GT and DDW can be written as $f\left(z_{t}, k_{t}\right)=\left(z_{t}-c\right) \cdot\left(k_{t}\right)^{\alpha}-F$ where $\mathrm{c}=0$ and $\log \left(\mathrm{z}_{\mathrm{t}}\right)=\mu+\rho \cdot\left[\log \left(\mathrm{z}_{\mathrm{t}}\right)-\mu\right]+\mathrm{e}_{\mathrm{t}}$ with $\mathrm{e}_{\mathrm{t}} \sim \mathrm{N}(0, \sigma)$.

In our extension, we allow $\mathrm{c}>0$ to create non-trivial bad outcomes for the gross profit function. However, making this allowance affects the average profitability. Moreover, changing $\mu$ to correct this effect changes the profitability variance. Consequently, we change $\mathrm{c}, \mu$, and $\sigma$ jointly to generate bad profit outcomes while keeping the median and variance of the profitability function unchanged when firms have steadystate capital. Specifically, we choose the $c_{0}, \mu_{0}$, and $\sigma_{0}$ values that numerically solve the following nonlinear system of equations:

(I) $\quad \operatorname{Median}\left[\mathrm{f}\left(\mathrm{z}_{\mathrm{t}}, \mathrm{kss}_{\mathrm{ss}} ; \mathrm{c}_{0}, \mu_{0}, \sigma_{0}\right) / \mathrm{kss}_{\mathrm{ss}}\right]=\operatorname{Median}\left[\mathrm{f}\left(\mathrm{z}_{\mathrm{t}}, \mathrm{kss}_{\mathrm{ss}} ; \mathrm{c}, \mu, \sigma\right) / \mathrm{kss}_{\mathrm{ss}}\right]$

$$
\text { Variance }\left[\mathrm{f}\left(\mathrm{z}_{\mathrm{t}}, \mathrm{kss}_{\mathrm{ss}} ; \mathrm{c}_{0}, \mu_{0}, \sigma_{0}\right) / \mathrm{kss}_{\mathrm{ss}}\right]=\operatorname{Variance}\left[\mathrm{f}\left(\mathrm{z}_{\mathrm{t}}, \mathrm{kss}_{\mathrm{ss}} ; \mathrm{c}, \mu, \sigma\right) / \mathrm{kss}_{\mathrm{ss}}\right]
$$$$
\mathrm{f}\left(\mu_{0}-3 \cdot \sigma_{0} / \sqrt{ }(1-\rho), \mathrm{kss}_{\mathrm{ss}} ; \mathrm{c}_{0}, \mu_{0}, \sigma_{0}\right) / \mathrm{kss}_{\mathrm{ss}}=\text { Low Profitability Target }
$$

which can be alternatively written as:

$$
\exp \left(\mu_{0}\right)-\mathrm{c}_{0}=\exp (\mu)
$$

$$
\left(\exp \left(\sigma_{0}\right)-1\right) \cdot \exp \left(2 \cdot \mu_{0}+\sigma_{0}\right)=(\exp (\sigma)-1) \cdot \exp (2 \cdot \mu+\sigma)
$$

$$
\left(\exp \left(\mu_{0}-3 \cdot \sigma_{0} / \sqrt{ }(1-\rho)\right)-\mathrm{c}_{0}\right) \cdot\left(\mathrm{kss}_{\mathrm{ss}}\right)^{\alpha-1}-\mathrm{F} / \mathrm{k}_{\mathrm{ss}}=-\varphi
$$

where $\varphi$ is the minimum profitability parameter of interest.

We consider five alternative values for the minimum profitability parameter. Specifically, $\varphi$ takes the alternative values of $0.03,0.06,0.09,0.12$, and 0.15 .

In the third and last extension, we add a lower bound on payouts so that firms are constrained to pay their equity investors (in dividends + repurchases) at least $\psi \cdot\left(\mathrm{k}_{\mathrm{t}}+\mathrm{c}_{\mathrm{t}}-\mathrm{d}_{\mathrm{t}}\right)$, with $\mathrm{k}_{\mathrm{t}}, \mathrm{c}_{\mathrm{t}}$, and $\mathrm{d}_{\mathrm{t}}$ representing the firm's 
capital, cash balances, and book debt (so that $\mathrm{k}_{\mathrm{t}}+\mathrm{c}_{\mathrm{t}}-\mathrm{d}_{\mathrm{t}}$ is the firm's book equity). ${ }^{3}$ We consider five alternative values for the payout constraint, with $\psi$ taking the alternative values of $0.02,0.04,0.06,0.08$, and 0.10 .

Table A1

\section{Calibration of Models in Gamba and Triantis (2008) and DeAngelo, DeAngelo and Whited (2011)}

The table provides our calibration for the parameters in two models that can be viewed as cash-balance-related extensions of Hennessy and Whited's (2005) dynamic tradeoff model: Gamba and Triantis (2008, GT) and DeAngelo, DeAngelo, and Whited (2011, DDW).

\section{Model Parameters}

$\mu$ : unconditional mean of productivity/profitability state variable

$\rho$ : autocorrelation of productivity/profitability state variable

$\sigma:$ standard deviation of productivity/profitability shocks

$\alpha$ : curvature of the profit function parameter

F: profitability fixed cost parameter

$\delta$ : capital depreciation rate

$\gamma_{0}$ : investment fixed adjustment cost parameter

$\gamma_{1}$ : investment smooth adjustment cost parameter

$\lambda_{0}$ : linear equity issuance cost parameter

$\lambda_{1}$ : quadratic equity issuance cost parameter

$\theta$ : linear debt issuance cost parameter

$\phi$ : agency cost of holding cash

$\mathrm{u}$ : upper bound on debt as a fraction of steady state capital

$\tau_{\mathrm{e}}$ : personal tax rate on equity income

$\tau_{\mathrm{d}}$ : personal tax rate on debt income

$\tau_{\mathrm{c}}$ : corporate tax rate

$\mu_{\tau}$ : mean of corporate tax rate progressive adjustment function

$\sigma_{\tau}$ : standard deviation of corporate tax rate progressive adjustment function

1: liquidation price of assets during voluntary sales

$\mathrm{s}$ : liquidation price of assets during fire sales

r: real interest rate

GT DDW

$\begin{array}{cc}0.0000 & 0.0000 \\ 0.7280 & 0.7280 \\ 0.3500 & 0.3500 \\ 0.4500 & 0.7880 \\ 1.3000 & 0.0000 \\ 0.1000 & 0.1500 \\ - & 0.0034 \\ - & 0.1519 \\ 0.0600 & 0.1615 \\ - & 0.0041 \\ 0.0200 & 0.0200 \\ 0.0035 & 0.0035 \\ - & 0.6000 \\ 0.1200 & - \\ 0.2500 & - \\ 0.3500 & 0.3500 \\ -12.267 & - \\ 9.2460 & - \\ 0.7500 & - \\ 0.5000 & - \\ 0.0500 & 0.0200\end{array}$

\footnotetext{
${ }^{3}$ Note that net payouts (dividends+repurchases-issuances) are still unconstrained. However, for the net payout to be lower than $\psi \cdot\left(\mathrm{k}_{\mathrm{t}}+\mathrm{c}_{\mathrm{t}}-\mathrm{d}_{\mathrm{t}}\right)$, the firm needs to pay the equity issuance adjustment cost present in the model. The constraint can be alternatively viewed as a replacement of the equity issuance adjustment cost function with a "low net payout" adjustment-cost function.
} 


\section{References}

Acharya, V., Almeida, H., Campello, M., 2007. Is cash negative debt? A hedging perspective on corporate financial policies. Journal of Financial Intermediation 16, 515-554.

Almeida, H., Campello, M., Weisbach, M., 2005. The cash flow sensitivity of cash. Journal of Finance 59, 1777-1804.

Binsbergen, J.H.v., Diamond, W., and Grotteria, M., 2021. Risk-free interest rates, Forthcoming Journal of Financial Economics.

DeAngelo, H., DeAngelo, L., Stulz, R., 2010. Seasoned equity offerings, market timing, and the corporate lifecycle. Journal of Financial Economics 95, 275-295.

DeAngelo, H., DeAngelo, L., Whited, T., 2011. Capital Structure dynamics and transitory debt. Journal of Financial Economic 99, 235-261.

DeAngelo, H., Gonçalves, A., Stulz, R., 2018. Corporate deleveraging and financial flexibility. Review of Financial Studies 31, 3122-3174.

DeAngelo, H., Roll, R., 2015. How stable are corporate capital structures? Journal of Finance 70, 373-418.

Denis, D., McKeon, S., 2012. Debt financing and financial flexibility: evidence from proactive leverage increases. Review of Financial Studies 25, 1897-1929.

Denis, D., McKeon, S., 2021. Persistent negative cash flows, staged financing, and the stockpiling of cash balances. Forthcoming Journal of Financial Economics.

Dittmar, A., Duchin, R., 2011. The dynamics of cash. University of Michigan and University of Washington working paper. Downloadable at https://papers.ssrn.com/sol3/papers.cfm?abstract id $=1569529$

Duchin, R., Gilbert, T., Harford, J., Hrdlicka, C., 2016. Precautionary savings with risky assets: When cash is not cash. Journal of Finance 72, 793-852.

Easterbrook, F., 1984. Two agency cost explanations of dividends. American Economic Review 74, 650659.

Fama, E., French, K., 2005. Financing decisions: Who issues stock? Journal of Financial Economics 76, 549-582.

Gamba, A., Triantis, A., 2008. The value of financial flexibility. Journal of Finance 63, 2263-2296.

Hamilton, J., 1994. Time Series Analysis. Princeton University Press. Princeton NJ.

Hennessy, C., Whited, T., 2005. Debt dynamics. Journal of Finance 60, 1129-1165.

Huang, R., Ritter, J., 2021. Corporate cash shortfalls and financing decisions. Forthcoming Review of Financial Studies.

Lemmon, M., Roberts, M., Zender, J., 2008. Back to the beginning: Persistence and the cross-section of corporate capital structures. Journal of Finance 63, 1575-1608. 
Moyen, N., 2004. Investment-cash flow sensitivities: Constrained versus Unconstrained firms. Journal of Finance59, 2061-2092.

Myers, S., and N. Majluf. 1984. Corporate financing and investment decisions when firms have information that investors do not have. Journal of Financial Economics 13: 187-221.

Opler, T., Pinkowitz, L., Stulz, R., Williamson, R., 1999. The determinants and implications of corporate cash holdings. Journal of Financial Economics 52, 3-46.

Rajan, R., Zingales, L., 1995. What do we know about capital structure? Some evidence from international data, Journal of Finance 50, 1421-1460.

Tauchen, G., 1986. Finite state Markov-chain approximations to univariate and vector autoregressions. Economics Letters 20, 177-181.

Titman, S., Tsyplakov, S., 2007. A dynamic model of optimal capital structure. Review of Finance 11,359400. 